\title{
La idea de Europa en Fichte
}

\author{
Fichte's Idea of Europe
}

\author{
Salvi TURRÓ \\ Universidad de Barcelona
}

Recibido: 17-09-2012

Aceptado: 29-01-2013

\section{Resumen}

La idea de Europa en Fichte constituye el término medio para la adecuada comprensión de sus tesis cosmopolitas y nacionalistas. El artículo, por un lado, determina el lugar sistemático (disciplinas aplicadas) que ocupa el tema europeo en la obra de Fichte, así como las estructuras teóricas de la Doctrina de la Ciencia (intersubjetividad, interacción cultural) que son aplicadas en sus análisis históricos. Por otro lado, se reconstruye su génesis de la idea de Europa y el papel del pueblo-nación en la construcción de la "república europea de los estados", destacando el horizonte federalista como núcleo central de su concepción.

Palabras clave: Fichte, idealismo alemán, Europa, filosofía política, filosofía de la historia, nacionalismo.

\begin{abstract}
A worthwhile approach to Fichte's both cosmopolitan and nationalist tenets must take into account his idea of Europe. Accordingly, the present paper attempts to locate the European argument as a recurrent thread in the whole of Fichte's thought. The theoretical traits of the Doctrine of Science which Fichte summons in his historical analyses (intersubjectivity, cultural interaction) are therefore highlighted. Besides, this paper reconstructs the origins and development of Fichte's idea of Europe, coupling it to the populist-nationalist drive towards the federalist scope of a "European republic of states".
\end{abstract}

Keywords: Fichte, German idealism, Europe, political philosophy, philosophy of history, nationalism. 


\section{Situación del tema en el pensamiento de Fichte}

Desde los trabajos de I.H. Fichte y G. Schmoller1, que inauguraron el estudio técnico de la filosofía práctica fichteana, es recurrente destacar la tensión, si no contradicción, entre la lógica internacionalista de su primera teoría jurídica (derecho de gentes y cosmopolita) y la importancia concedida, especialmente a partir de 1806, al hecho nacional alemán. En unas lecturas se privilegia la posición cosmopolita, haciendo del nacionalismo algo subsidiario y políticamente instrumental, integrable fácilmente en aquella dimensión ${ }^{2}$; en otras, se subraya cómo la especificidad de la tesis nacionalista resulta incompatible con todo planteamiento republicano-cosmopolita ${ }^{3}$. A pesar de su diferente orientación, ambas interpretaciones coinciden en dejar en la penumbra el término medio al que, sin embargo, Fichte alude en múltiples ocasiones: el de la realidad europea como horizonte concreto en que plantear aquella discusión ${ }^{4}$. Reconstruir los elementos fundamentales que vertebran la comprensión fichteana de Europa y mostrar cuáles son las ambigüedades y aporías que comportan en relación al nacionalismo y al cosmopolitismo: tales son los objetivos de este trabajo. Por tratarse de un estudio estrictamente historiográfico, no entraremos en las críticas valorativas o cuestiones sistemáticas a que puede dar lugar la posición fichteana: temas estos que sólo pueden plantearse adecuadamente después de haber logrado aquella reconstrucción. No obstante, si la comprensión fichteana ya revela por sí sola una problematicidad esencial y sig-

${ }^{1}$ I.H. Fichte, Die philosophischen Lehren von Recht, Staat un Sitte von der Mitte der 18 Jhdts bis zum Gegenwart, Leipzig, 1850; G. Schmoller, J.G. Fichte. Eine Studie aus dem Gebiete der Ethik und der Nationalökonomie, Leipzig, 1865.

2 Son estudios clásicos en esta línea interpretativa: F. Meinecke, Weltbürgertum und Nationalstaat, Munich, 1908; R. Strecker, Die Anfänge von Fichtes Staatsphilosophie, Leipzig, 1916; G. Leibholz, Fichte und die demokratische Gedanke. Ein Beitrag zur Staatslehre, Friburgo, 1921; M. Buhr, Revolution und Philosophie. Die ursprüngliche Philosophie J.G. Fichtes und die französische Revolution, Berlín, 1965; A. Renaut, Le système du droit. Philosophie et droit dans la pensée de Fichte, París, 1986. En el ámbito de las redes de investigación europeas más recientes consagradas a Fichte véase: W.H. Schrader, "Nation, Weltbürgertum und Synthesis der Geisterwelt" en FichteStudien, vol. 2, 1990; R. Lauth, "Der letzte Grund von Fichtes Reden an die Deutsche Nation" en Fichte-Studien, vol 4, 1992; H.J. Becker, Fichtes Idee der Nation und das Jundentum, Amsterdam, Rodopi, 2000; J. Rivera, "Nationalisme et cosmopolitisme" en Fichte et la politique (J.Ch. Goddard y J. Rivera, edts.), Milán, Polimetrica, 2008.

3 Estudios clásicos de esta lectura son: Ch. Andler, Les origines du socialisme d'état en Allemagne, París, 1897; B. Bauch, Fichte und die deutsche Staatsgedanke, Langensalza, 1925; G.A. Walz, Die Staatsidee des Rationalismus und der Romantik und die Staatsphilosophie, Marburgo, 1928; R. Löchs, Die Theologie der Lehre Fichtes von Staat und Nation, Michelstadt, 1957; B. Wilms, Die totale Freiheit. Fichte politische Philosophie, Colónia, 1967. Entre les investigaciones más actuales véase especialmente: C. De Pascale, "Der Primat Deutschlands bei Fichte" en Fichte-Studien, vol. 3, 1991; G. Geismann, "Fichtes 'Aufhebung' des Rechtsstaates" en Fichte-Studien, vol. 3, 1991; M. Marcuzzi, "Ce qui fait qu'un peuble est un peuple selon Fichte" en Fichte et la politique, Milán, Polimetrica, 2008; I. Radrizzani, "Nation-contrat ou nation-génie? Les diverses figures de la nation chez Fichte" en Fichte et la politique, Milán, Polimetrica, 2008.

4 Esta línea interpretativa es utilizada en parte por G. Zöller, "Nation commune. L'idée fichtéenne d'une histoire universelle de l'Europe au point de vue cosmopolitique" en Fichte et la politique, Milán, Polimetrica, 2008. 
nificativa para la idea de un proyecto político europeo, este estudio tampoco estará exento de actualidad pues, desde la génesis histórico-conceptual, arrojará luz sobre un momento como el nuestro que parece escindirse nuevamente entre lo común y lo nacional -por no decir entre lo europeo y lo germánico.

La primera referencia relevante a la temática de Europa, dentro del marco conceptual de la Doctrina de la Ciencia5, se encuentra en su Recensión de "La Paz Perpetua" de Kant de 1796, publicada mientras elaboraba el curso y la edición del Derecho Natural6. Manifestando, en plena adhesión al opúsculo kantiano, que "frente a la opinión contraria, hay que observar que esta idea principal [paz perpetua] puede ser algo más [que un deseo piadoso, un proyecto desmesurado, un bello sueño], que quizá puede demostrarse tan estrictamente como otras disposiciones originarias, que radica en la esencia de la razón, que la razón exige absolutamente su realización y que, por tanto, pertenece a aquellos fines de la naturaleza que, si bien pueden ser demorados, no pueden ser aniquilados"7, Fichte destaca finalmente los indicios históricos que avalan su efectuación:

Dos fenómenos nuevos en la historia mundial aseguran el logro de este fin [paz perpetua]: el floreciente Estado libre norteamericano erigido en el otro hemisferio, desde el cual han de extenderse necesariamente la ilustración y la libertad sobre las partes del mundo oprimidas hasta ahora; y la gran república europea de Estados que, al contener la irrupción de los pueblos bárbaros por obra de la cultura de un modo que no se había dado en el mundo antiguo, garantiza la perduración de los Estados e incluso que cada uno en particular alcance con el tiempo una situación de equilibrio con los demás. ${ }^{8}$

Si el pasaje ya es relevante por conceptualizar la "república europea de Estados" (europäische Staatenrepublik) en paralelo a la unión de estados norteamericanos, y hacerlo en defensa del proyecto kantiano de una "federación de pueblos" (Völkerbund) 9 o un "estado de pueblos" (Völkerstaat $)^{10}$ como condición inherente al ius gentium, quizá lo es aún más porque la efectuación de tal exigencia jurídica en el caso de Europa se concreta -a diferencia de Norteamérica- en una situación peculiar: una pluralidad de Estados definidos por compartir una cultura edificada sobre las invasiones germánicas y el mundo antiguo. Se

\footnotetext{
5 Aunque en los escritos políticos de 1793 (Contribuciones para corregir el juicio del público sobre la revolución francesa, Reivindicación de la libertad de pensamiento a los príncipes europeos) se encuentran elementos que preludian posiciones posteriores, dado el carácter primerizo de estos textos y por tratarse de ensayos previos al andamiaje conceptual de la Doctrina de la Ciencia, prescindimos de referirnos a ellos.

6 Para la relación entre ambos textos, véase: S. Turró, "Réception de La paix perpetuelle par Fichte" en Fichte et la politique, Milán, Polimetrica, 2008.

7 Rezension zu Kants "Zum ewigen Frieden" (GA, I/3, 221). Como es habitual citamos a Fichte por la edición crítica de la Academia de Ciencias de Baviera [GA: sección/volumen, página]: para los textos mayores y más relevantes para nuestro tema referenciamos el título alemán por las siglas indicadas en la primera cita, para el resto de obras daremos el título completo.

8 Ibid. (GA, I/3, 228).

9 Kant, Zum ewigen Frieden (Ak, VIII, 354). Citamos Kant, como es habitual, por la edición de la Academia Prusiana de Ciencias [Ak], indicando el volumen en cifras romanas y la página en árabes. 10 Ibid. (Ak, VIII, 357).
} 
enuncian así los tres ejes que vertebrarán toda la reflexión de Fichte sobre Europa: horizonte jurídico federativo, unidad cultural y a la vez diversidad fáctica de pueblos-estados ${ }^{11}$. Pero este pasaje también sugiere la problemática síntesis de estos tres ejes y, por tanto, de la misma realidad europea: ¿en qué consiste la unidad que daría pleno sentido a tal "república" de Estados? No existiendo unidad política alguna en 1796, ¿debe entenderse sólo como un dinamismo tendencial? Pero aún en este caso, ¿se trata de una tendencia a la federación en sentido fuerte -en analogía al "Estado libre norteamericano"-, o sólo a una situación frágil de equilibrio fáctico de potencias? En el último caso, ¿podría hablarse propiamente de "república" europea con pleno sentido político, o su "grandeza" (die grösse europäische Republik) sólo tendría un sentido cultural?

Dada la concepción fichteana del sistema filosófico y su división interna ${ }^{12}$, el tema de Europa no se sitúa en el nivel apriórico-constructivo de las disciplinas transcendentales. Son ciertamente demostrables con plena evidencia proposiciones jurídicas como que, frente a la situación bélica natural, "los diversos Estados habrían de federarse para mantener entre ellos una relación jurídica"13; o que, por la equivalencia entre derecho y facultad coactiva14, "la federación ha de poder ejecutar sus sentencias [...] y, por tanto, la federación ha de estar armada"15. Pero que tales o cuales Estados particulares hayan de entrar o no en una misma federación en virtud de ciertas características culturales o históricas no se desprende en absoluto de aquellos principios jurídicos, sino que remite a cuestiones de facto irreductibles a la construcción transcendental.

Que "el ser racional finito no puede atribuirse a si mismo una causalidad libre en el mundo sensible sin atribuirla también a otros y, por tanto, sin admitir otros seres racionales finitos"16 de modo que "yo sólo puedo exigir a un determinado ser racional que me reconozca como un ser racional en la medida que yo mismo lo trato como tal"17, y que, por tanto, "el hombre (así como todos los seres finitos en general) sólo llega a ser hombre entre hombres [...], y todos los individuos han de ser educados para llegar a ser hombres, pues en caso contrario no llegarían a serlo"18: tales enunciados son afirmaciones derivadas de la estructura transcendental de la conciencia -el "fundamento" de toda la Doctrina de la Ciencia de 1794- y, en consecuencia, absolutamente necesarias. Pero que un individuo forme parte de este o aquel colectivo humano, que esta o aquella comunidad se caractericen por uno u otro rasgo esencial, que estas colectividades mantengan relaciones de afinidad o diferencia con estas otras, etc. son cuestiones fácticas que, en todo caso, se inscriben en el marco de una "antropología pragmática" o historia sociocultural.

11 Como puede verse en las lecciones 11, 13 y 14 de Los caracteres de la edad contemporánea, para referirse a la comunidad política europea Fichte utiliza indistintamente ambas expresiones: Staatenrepublik y Völkerrepublik.

12 Wissenschaftslehre Nova Methodo (GA, IV/2, 262-266; IV/3, 520-523). En la literatura secundaria véase especialmente: R. Lauth, "Fichtes Gesamtidee der Philosophie" en Philosophisches Jahrbuch, $\mathrm{n}^{\mathrm{o}}$ 71, Munich, 1964.

13 Naturrecht [NR] (GA, I/4, 159).

14 NR (GA, I/3, 430, 432).

$15 \mathrm{NR}(\mathrm{GA}, \mathrm{I} / 4,161)$.

$16 \mathrm{NR}(\mathrm{GA}, \mathrm{I} / 3,340)$.

$17 \mathrm{NR}(\mathrm{GA}, \mathrm{I} / 3,352)$.

$18 \mathrm{NR}(\mathrm{GA}, \mathrm{I} / 3,347)$. 
Pues bien, si en la comprensión de Europa intervienen a la vez exigencias jurídicas y elementos empíricos, ello significa que su esclarecimiento conceptual habrá de encontrarse en el ámbito de los saberes "filosófico-históricos"19: conocimientos que "se fundamentan en parte en la experiencia [...], pero no son meramente históricos, pues he de relacionar el fin -que sólo puede conocerse filosóficamente- a los objetos dados en la experiencia para poder juzgarlos como medios para la consecución de aquel fin" 20 . Y, en efecto, dos son las disciplinas "intermedias" en cuyo entrecruzamiento el tema europeo encuentra su lugar natural en la obra de Fichte: la filosofía política y la filosofía de la historia. Tal ubicación conlleva dos consecuencias hermenéuticamente relevantes. Por un lado, que sus análisis no aspiran a la apodicticidad propia del procedimiento intuitivo-genético de la construcción transcendental, sino que se trata de una certeza empíricamente condicionada ya que, una vez se ha establecido el marco conceptual de los principios, "acaba la tarea del filósofo y empieza la del observador del mundo y de los hombres" 21 . No es así de extrañar que estos análisis fichteanos -y los textos respectivos- no tengan tanto el carácter de doctrinas filosóficas clausuradas cuanto de ensayos, sugerencias, propuestas revisables y también de aporías, pues se trata de articular dos elementos heterogéneos aunque igualmente necesarios para la comprensión de lo real.

Ahora bien, el hecho de que la adecuada intelección de las sociedades, pueblos, naciones o Estados en su devenir no puede efectuarse sólo desde los principios del derecho, sino que implica evaluar elementos culturales e históricos concretos, no significa que Fichte confunda el ámbito jurídico con el moral, cultural o pedagógico, ni tampoco que reduzca lo deontológico al plano de lo contingente 22 , sino justo lo contrario: sólo mediante el conocimiento más completo posible de lo fáctico -Europa como unidad y diversidad de pueblos y Estados- las exigencias e ideales del derecho -constitucionalismo, federalismo, cosmopolitismo- podrán alcanzar su plena realización en una "república europea". En palabras de R. Schottky: "ningún individuo es exclusivamente sujeto de derecho, es siempre también un destinatario de deberes morales, un portador históricamente acuñado de una cultura transpersonal, y mucho más. Así los hombres no pueden coexistir como miembros de una comunidad jurídica en la reciprocidad que produce una vida conforme a derecho sin que también tengan lugar entre ellos interacciones culturales y morales que, por su parte, tienen un efecto retroactivo sobre el curso de la vida conforme a derecho"23.

19 Para el lugar y función de estas disciplinas en el pensamiento de Fichte, véase: I. Radrizzani, "Filosofia transcendentale et prassi política in Fichte" en Filosofia transcendentale et destinazione ètica (A. Masullo y M. Ivaldo, edts.) Nápoles, Guirini e Associati, 1995, p. 343-349.

20 Vorlesungen über die Bestimmung des Gelehrten (GA, I/3, 53).

21 Grundzüge des gegenwärtigen Zeitalters [GgZ] (GA, I/8, 197).

22 Es habitual caracterizar la filosofía práctica de la segunda época de Fichte por tal confusión de esferas, frente a su estricta separación en el período de Jena -véase el comentario clásico de HJ. Verweyen, Rechts und Sittlichkeit in J.G. Fichtes Gesellschaftslehre, Friburgo, Alber Verlag, 1975. Sin embargo, esta interpretación no destaca suficientemente la diferencia de objetos sobre los que versan los análisis fichteanos en cada momento y obra: mientras que el interés por los principios transcendental-aprióricos de cada disciplina filosófica domina en la primera época, en la segunda el centro de atención pasa a ser la comprensión fáctica de las realidades sociales que, como tal, exige moverse entre las diversas disciplinas teóricas y las consideraciones empíricas.

23 R. Schottky, "Rechtstaat und Kulturstaat bei Fichte. Eine Erwiderung" en Fichte-Studien, vol. 3, 1992, p. 134. 
Se entiende así otro aspecto del discurso fichteano: el del filósofo transcendental como consejero áulico, siguiendo el precedente kantiano en los dos apéndices finales de La paz perpetua. En efecto, la conjunción de reflexión política y filosofía de la historia es lo único que posibilitará una acción política eficaz, es decir, cuyo objetivo sea que "el estado real [...] se aproxime lentamente al estado racional"24. Por eso, la comprensión de Europa será también necesariamente la elaboración de un proyecto político para efectuar cuanto comporta tal idea. Resulta así, no sin cierta paradoja, que es justamente en las disciplinas intermedias y aplicadas -y no en las puramente transcendentales- donde la filosofía muestra su máxima potencialidad productiva: "aplicar la filosofía significa ser la verdadera fuerza fundamental que configura el mundo en la vida, en la acción y en la creación, y ponerse al frente de la configuración del mundo en el sentido más propio y supremo" 25 .

La tematización de Europa -como, en general, todas las cuestiones filosófico-históricas- tiene lugar principalmente en los textos fichteanos de la segunda época. Una vez desplegadas en el período de Jena los fundamentos de las disciplinas transcendentales, en su "segunda navegación"26 Fichte dirigirá preferentemente su atención a las dificultades empíricas que, a raíz de las guerras napoleónicas, condicionan la viabilidad y futuro de las naciones europeas y del Estado de derecho inaugurado por la revolución francesa. Además de algunos opúsculos de 1807 (El patriotismo y su opuesto, Sobre Maquiavelo, La república de los alemanes), cuatro son textos fundamentales para nuestro tema: Los caracteres de la edad contemporánea de 1805, los Discursos a la nación alemana de 1808, el apartado sobre el derecho de gentes en la Doctrina del derecho de 1812, y su último curso universitario, "sobre diversos contenidos de filosofia aplicada"27, conocido usualmente como Doctrina del Estado (1813).

\section{El sustrato antiguo}

Como se avanzaba en el pasaje citado de 1796, para Fichte el crisol de Europa se sitúa en la confluencia del mundo antiguo y la irrupción de los pueblos bárbaros: el primero constituye un sustrato cultural ya extinto pero que, perdurando de algún modo a través de los tribus germánicas, sigue determinando la Europa moderna en su "plural unidad" de Estados.

\footnotetext{
24 Der geschlossene Handelstaat [gHS] (GA, I/7, 51).

25 Staatslehre [StaL] (GA, II/16, 30).

26 Por lo que se refiere al nivel estrictamente transcendental, en su segundo período (especialmente a partir de 1804) Fichte se ocupa básicamente de revisar (en sus cursos inéditos) el "fundamento último" de la relación entre la conciencia y el absoluto en diálogo con la filosofía de Schelling, manteniendo sin alteraciones relevantes -en todo caso, haciéndolos depender ahora del nuevo "fundamento absoluto"- los principios internos de la filosofía práctica de Jena. Es en el campo de las disciplinas "aplicadas" - de hecho, la mayor parte de los textos publicados en la segunda época- donde encontramos los frutos de los principios prácticos antes elaborados y especialmente respecto a la cuestión de Europa que aquí nos ocupa. En este sentido, nos adherimos a la lectura continuista-evolutiva del pensamiento fichteano, cuya "segunda navegación" profundiza y amplia el horizonte ganado en la primera etapa (véase: S. Turró, Op. cit., pp. 144-147).

$27 \mathrm{StaL}(\mathrm{GA}, \mathrm{II} / 16,15)$.
} 
¿Qué caracteriza esencialmente el mundo antiguo? Dado que se trata de efectuar un análisis filosófico-histórico y no sólo de recopilar datos empíricos, Fichte tendrá que utilizar un esquema conceptual que permita desvelar las líneas de fuerza fundamentales de la antigüedad. Dos son los ejes de tal modelo, ambos deudores por igual del análisis transcendental de la conciencia.

(1). Como nuestro objeto de estudio son fenómenos relativos a comunidades humanas y sus interacciones, el esquema conceptual-interpretativo habrá de basarse en el principio de la intersubjetividad28: toda forma de conciencia emerge en el espacio abierto por la "exhortación" (Aufforderung) al ejercicio de la libertad en vistas al mutuo reconocimiento (Anerkennung). Tal principio implica que las colectividades, como los individuos, no pueden existir sin mediar instrumentos de comunicación e interacción: cada pueblo tiende a "formar la capacidad de comunicar su cultura y procurarse una poderosa influencia y eficiencia”29, generándose así una dinámica de acción y reacción de unos pueblos con otros. Fichte concreta empíricamente tales interacciones valiéndose, como ha señalado G. Zöller ${ }^{30}$, de un modelo deudor de la mitología e historiografía antiguas: la confrontación entre "autóctonos" (Erdgeborene, Urbewohner) -de entrada clausurados en su propia tradición- y pueblos migratorios a través de cuyo encuentro con los autóctonos se generan las innovaciones culturales ${ }^{31}$.

(2). Por otro lado, toda posición de la conciencia en el mundo presupone la labor esquematizadora de la imaginación 32 . Pero "hay dos maneras fundamentales de imaginar, es decir, dos conceptos fundamentales de imagen: por una parte, el ser dado y simplemente presente; por otra, el ser a producir por la libertad; la naturaleza y la moralidad"33. De ahí que sean posibles (transcendentalmente) dos posiciones que subyacen a todas las concreciones empírico-culturales de la historia humana: la primera (ser-dado, naturaleza) tiende a la fijación y cosificación de toda realidad, incluida el propio ser humano; la segunda (libertad, moralidad) tiende a la actividad continuada en pos de los fines absolutos de la razón. Tenemos, por tanto, dos tendencias determinantes de la organización de los pueblos: un modelo de soberanía paternalista y despótica y otro centrado en las exigencias racionales de la libertad. En el primer caso, "el Estado y su constitución son una ordenación absolutamente divina sobre la que no es preciso reflexionar y que deniega completamente el ejercicio del entendimiento; una cuestión de fe para todo el mundo: para los fundadores fe natu-

\footnotetext{
28 Sobre la importancia de la estructura transcendental de la intersubjetividad en la filosofía de la historia de Fichte, véase: K. Hahn, "Die Idee der Nation als Implikat der Interpersonalitäts- und Geschichtestheorie" en Fichte-Studien, vol. 2, 1990.

$29 \mathrm{GgZ}(\mathrm{GA}, \mathrm{I} / 8,330)$.

30 G. Zöller, Op. cit., p. 355.

${ }^{31} \mathrm{GgZ}$ (GA, I/8, 300, 333), Reden an die Deutsche Nation [RDN] (GA, I/10, 144), StaL (GA, II/16, 110).

32 Tomando como punto de partida la noción kantiana de "esquema" como producto a priori de la imaginación transcendental, Fichte amplía su sentido incluyendo -además de los esquemas cognoscitivos- las estructuras determinantes del ámbito práctico y justificando la reciprocidad entre unos y otros. Con ello, de la esquematitzación imaginativa dependen las dos formas de constituir el "mundo" como totalidad teórico-práctica.

${ }^{33} \mathrm{StaL}(\mathrm{GA}, \mathrm{II} / 16,104)$.
} 
ral, para los subordinados fe en la autoridad"34. En el segundo, el Estado aparece "como un medio y una preparación de las condiciones para resolver la tarea originada por el arte de la libertad: la institución del reino [de la razón]"35.

Haciendo uso de este doble modelo teórico, Fichte caracteriza la antigüedad por dos rupturas. El primer corte se produce entre Asia y Europa o, más exactamente, entre Asia y el mundo grecolatino. La forma más elemental de relación entre los pueblos pasa por la guerra, cuyo desenlace significa "la sumisión de los pueblos libres para ciertos fines del pueblo dominante"36: surgen así los grandes imperios esclavistas asiáticos, basados en el sometimiento indiscriminado y arbitrario al poder absoluto del sátrapa respectivo. Frente a tales estados, dotados ya de una administración interna, Europa era "originariamente sólo el asiento del salvajismo"37. Los salvajes europeos que habitaban Grecia aprendieron de los imperios orientales - como conservaron en la memoria sus mitos fundacionales- sus conocimientos artesanales y también la necesidad de una organización política, pero, dada su fragmentación territorial y sus luchas intestinas, "en esta primera zona culturizada de Europa no surgió, como en Asia, un imperio extenso sino diversos pequeños estados" 38 . El enfrentamiento entre ellos y de ellos con Asia, favoreció que "los súbditos libres de estos nuevos estados [...] no aceptaran ciegamente y sin la menor duda las exigencias y disposiciones de su gobernante, sino que querían entender ellos mismos cómo revertían sobre el bienestar general"39. Frente al despotismo asiático, Grecia significa así la aparición de la libertad política y sus implicaciones jurídicas, convirtiéndose en la protofigura de Europa: "a partir de tales circunstancias empezó a desarrollarse el agudo sentido por el derecho, a mi parecer el verdadero rasgo característico de los pueblos europeos en oposición con la resignación y el sometimiento propios de Asia"40.

Ahora bien, el paso del despotismo a la libertad no es inmediato. La historia política tanto de Grecia como de Roma muestran cómo la libertad sólo puede desarrollarse bajo una nueva oposición en que reaparece, a otro nivel, el impulso despótico: los conflictos entre las tendencias aristocráticas de los eupátridas o patricios y las democráticas del démos o la plebe ${ }^{41}$. Este enfrentamiento se resuelve por el establecimiento de instituciones y procedimientos electivos que equilibran ambas fuerzas, es decir, por el mecanismo de mediación que denominamos "constitución" 42 . Ciertamente este instrumento jurídico no impidió la aparición periódica de dictadores, usurpadores o tiranos, pero tales figuras ya no eran equiparables al déspota asiático: justamente por ser el tirano "quien detenta el poder contra una constitución o bien claramente expresada o bien presente en la creencia general del pueblo", su acción política se enmarca vollens nollens en el horizonte constitucional al que se opone,

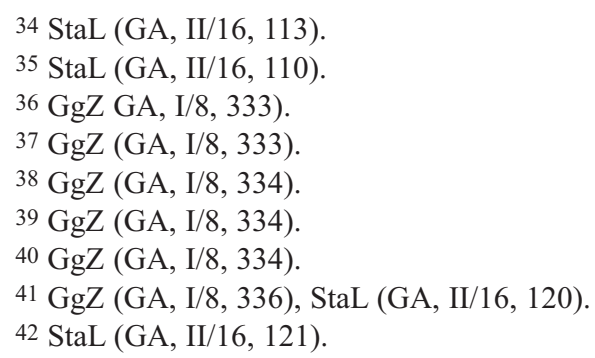


pues "sólo hay tiranos en época de constituciones"43. En esta perspectiva, la evolución política romana puede considerarse como el surgimiento y sucesivo perfeccionamiento de "una maestría en la legislación civil y en la administración interna y externa del Estado [...] como ninguna nación ha poseído antes de Roma" 44 . Por ello, con su expansión y la incorporación del resto de pueblos europeos a su cultura, el imperio romano "completa la totalidad de la época antigua" 45 bajo el principio del derecho: "libertad civil, participación en el derecho de todos los nacidos libres, sentencias judiciales según la ley, administración financiera según principios"46.

La segunda ruptura determinante en la génesis de Europa tiene lugar respecto a la totalidad del mundo antiguo, incluido el "Estado de derecho" romano: tal es la aparición del cristianismo. Si hasta aquí el análisis de la antigüedad se ha centrado en el aspecto sociopolítico, ahora Fichte destacará el papel del elemento religioso, esencial para comprender íntegramente la experiencia humana del mundo. Lo específico de la religiosidad antigua -tanto asiática como judaica, griega o romana- es su carácter de "religión política": es religatio a la divinidad a través de los rituales y sacrificios exigidos para cumplir sus mandatos ${ }^{47}$, pero, a su vez y de modo inseparable, estos elementos cúltico-estatutarios se asocian a la vida de los estamentos y magistraturas públicas, desde el culto a los dioses familiares 48 a la sanción de las leyes y las guerras por las divinidades de la ciudad ${ }^{49}$. Con ello, tanto las instituciones como el aparato administrativo del derecho, que en principio expresan el dinamismo esquematizador de la libertad, quedan finalmente referidos a los mecanismos rituales de una pietas dependiente de la esquematización substancial-natural de lo divino. De aquí que Fichte pueda concluir genéricamente que "los Estados de la antigüedad eran teocracias; el pueblo era el instrumento de dios que quería manifestar su poder y soberanía abarcando un imperio universal; a partir del Estado romano se logró prácticamente este fin" 50 . Componente teocrático que explica la forma monárquica final de la historia romana ${ }^{51}$.

Pues bien, frente a la religiosidad cúltica y estatutaria de los antiguos, el cristianismo introduce un principio religioso-filosófico radicalmente diferente52: "la libertad es la substancia absoluta visible en cuanto visibilidad -condición de la visibilización- de la voluntad divina, es decir, de la esencia interna de Dios y de su imagen"53. Manifestándose la divinidad en la conciencia libre, la coherencia y consistencia plenas del hombre como imago Dei se juegan ahora exclusivamente en la comprensión (razón) y realización (praxis) de las exi-

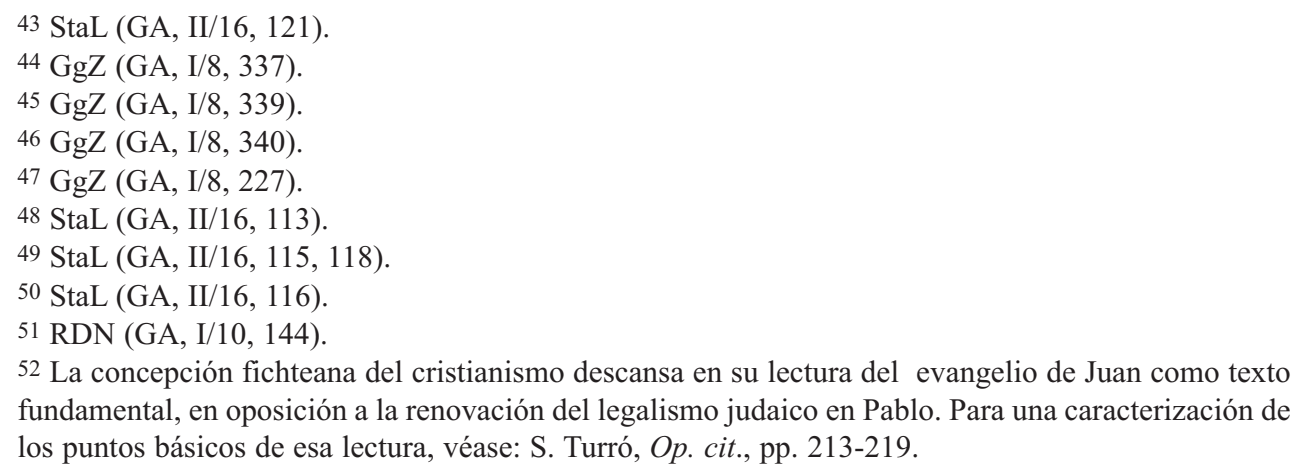
$53 \mathrm{StaL}(\mathrm{GA}, \mathrm{II} / 16,131)$. 
gencias intersubjetivas (jurídicas y morales) de la libertad. Si bien es cierto que "el concepto unitario del cristianismo es esencialmente el de Reino de los cielos" 54 , tal Reino no consiste en el mero legalismo externo del derecho y de la religión de la ciudad antigua, ni en su hipostatización transcendente en otro mundo, sino que "ha de ser él mismo la disposición a una radical recreación histórica del género humano" 55.

Emergen así la convicción y evidencia interiores de una transformación de lo real en pos de los ideales racional-morales a efectuar en todos y cada uno de los miembros de la especie: "el cristianismo es el evangelio de la libertad y de la igualdad [...], el evangelio de la reconciliación y la redención" 56. La concepción romana del Estado y del derecho, comparada con tal exigencia de moralidad absoluta (interna y externa), aparece ahora como deficitaria: ciertamente era un "Estado de derecho al menos formalmente" 57 , pero consistía en un sistema de garantías legales referidas exclusivamente a los "ciudadanos", con total exclusión del resto de seres humanos, extranjeros o esclavos 58 . A partir del cristianismo "el fundamento de los derechos es la humanidad [...]; en la antigüedad no era cuestión de humanidad, sino solamente de ciudadanía"59. Este cambio de perspectiva es tan esencial que, en el análisis fichteano, la "buena nueva" cristiana significa la génesis de un verdadero "nuevo mundo" (neue Welt) que comporta desde su misma aparición la muerte del "antiguo", aunque creciera y se extendiera dentro de él. Si el vino nuevo no puede contenerse en odres viejos, "esta religión quería y debía llegar a ser el principio creador de un nuevo estado, por lo cual el antiguo, incapaz de renovación, tenía que desaparecer"60. Este "nuevo mundo" es propiamente el de la "historia moderna" (neuere Geschichte)61 y, por tanto, de la Europa actual.

\section{La unidad europea: el imperio cristiano}

En su forma final en Roma, la cultura del mundo antiguo se caracteriza, pues, por una tensión irresuelta: el principio despótico (asiático) es superado "formalmente" por el derecho romano, pero a la vez es conservado en el aspecto teocrático de una religión política que acaba imponiendo un gobierno despótico-imperial a todos los pueblos. El cristianismo, al criticar la religiosidad estatutaria y aspirar a la realización material de la libertad e igualdad de todos los hombres sin distinción, se contrapone esencialmente al Estado romano. Pero justamente porque exige aquella realización en la tierra, no puede tampoco contentarse con una revolución interior de la conciencia (moralidad, deber, iglesia), sino que quiere su visibilidad en las relaciones objetivas (derecho, Estado): “con esta religión surgiría una opinión pública del estado total de la cultura, y en ella un soberano (en absoluto insignificante) sobre

\footnotetext{
$54 \mathrm{StaL}(\mathrm{GA}, \mathrm{II} / 16,136)$.

$55 \mathrm{StaL}(\mathrm{GA}, \mathrm{II} / 16,133)$.

$56 \mathrm{StaL}(\mathrm{GA}, \mathrm{II} / 16,132)$.

$57 \mathrm{GgZ}(\mathrm{GA}, \mathrm{I} / 8,340)$.

$58 \mathrm{StaL}(\mathrm{GA}, \mathrm{II} / 16,117-118)$.

$59 \mathrm{StaL}(\mathrm{GA}, \mathrm{II} / 16,118)$.

$60 \mathrm{GgZ}(\mathrm{GA}, \mathrm{I} / 8,340)$.

$61 \mathrm{StaL}(\mathrm{GA}, \mathrm{II} / 16,131)$.
} 
los soberanos, que concedería a éstos toda la libertad para hacer el bien, pero que les limitaría frecuentemente el placer de hacer el mal"62. Es decir, la superación cristiana del imperio romano sólo podía consistir en el surgimiento de un nuevo "imperio cristiano". En este marco, no exento de tensiones, irrumpieron los pueblos bárbaros:

\begin{abstract}
Estas estirpes germánicas, presumiblemente de un mismo origen y con una antigua conexión con los griegos -como un examen profundo de sus respectivas lenguas podría demostrar indiscutiblemente-, habían permanecido en sus bosques en un grado de cultura parecido al de los griegos en su época heroica [...]. Su culto a los dioses era muy simple, como sus costumbres, y apenas surgían en ellos dudas sobre su dignidad moral. Por hábitos milenarios, la independencia, la libertad y la igualdad de todos llegaron a ser algo connatural en ellos 63 .
\end{abstract}

Arraigado sentimiento de libertad-igualdad y afirmación de independencia respecto a todo poder unitario-despótico serán los rasgos característicos de la nueva Europa. Como prueba empírica, Fichte apela al conocido testimonio de Tácito sobre los primitivos germanos $^{64}$, así como al sistema de lealtades personales (comitates) ${ }^{65}$ que determinaba las vinculaciones feudales entre los distintos linajes ${ }^{66}$. Esta tendencia irrefrenable a la autonomía personal y colectiva tenía que comportar necesariamente la fragmentación de la antigua unidad territorial y administrativa romana. De ahí el surgimiento de las nuevas estructuras políticas claramente descentralizadas que caracterizan el Medievo: las ciudades libres alemanas e italianas ${ }^{67}$, la pluralidad de principados integrantes del Sacro Imperio 68 y su constitución federal basada en la "tradicional república de pueblos"69.

Ahora bien, esta tendencia disgregadora - con los conflictos bélicos que le son inherentes- se desarrolló al amparo cultural y religioso del cristianismo. Y como la Iglesia, desaparecido el poder coercitivo de la antigua Roma, no podía ejercer un dominio directo sobre las nuevas entidades feudales, tuvo que limitarse a educarlas, transmitiéndoles su fe en el destino moral común a todo el género humano $\mathrm{y}$, por tanto, la exigencia de respeto y reconocimiento mutuos entre los diferentes individuos y clanes. De este modo, más allá de la diversidad de usos, costumbres o lenguas de los distintos pueblos, el cristianismo generó la representación de su pertenencia a una unidad superior fundada en relaciones de reciprocidad reglada: "la religión se convirtió en la supervisora del derecho de gentes"70. Derecho que estableció un marco -aunque sólo fuera "ideal"- de vinculación de los diferentes pueblos a unos mismos principios ${ }^{71}$ : aceptación de la soberanía e independencia de cada territorio, prohibición de toda guerra de exterminio y reconocimiento de la necesidad de una paz

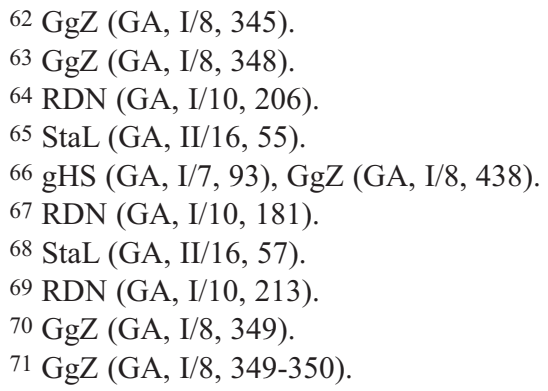


permanente. Tal horizonte internacionalista jurídico-político propició la existencia fáctica de un verdadero cosmopolitismo europeo: sus habitantes "se mezclaban unos con otros, viajaban, practicaban el comercio y el intercambio, se prestaban servicios y cada cual, habiendo llegado a la región del otro, creía todavía estar en su casa"72. Libertad de desplazamiento y de circulación de mercancías que configuró la Europa cristiana como un único "gran estado comercial" que "en sus rasgos fundamentales aún perdura en los tiempos actuales"73.

La comprensión fichteana de la Europa medieval viene determinada, por tanto, por la interacción del elemento diversificador de la libertad tribal germánica con el elemento unificador del cosmopolitismo cristiano. Y en la medida que, desde el Fundamento de toda la Doctrina de la Ciencia de 1794, la síntesis entre unidad y pluralidad remite a la categoría de reciprocidad (Wechselwirkung), aquella comprensión equivale a definir Europa ciertamente como una "entidad", pero no en sentido substancial-natural (cosificado y muerto), sino en cuanto proceso (intersubjetivo) de interacción entre sus partes: cada una de éstas no es nada sin la relación con las otras y tal dinamismo conjunto define la identidad europea. De ahí que, en la terminología fichteana, el "imperio cristiano de los pueblos" (christliche Völkerreich $)^{74}$ no consista tanto en una realidad política bajo una soberanía unificada -el Sacro Imperio Romano Germánico- cuanto en el dinamismo de reciprocidad cultural-jurídica de sus integrantes en pie de igualdad, esto es, en la "república cristiana de los pueblos" (christliche Völkerrepublik)75. En este sentido, ciertamente "los pueblos de la nueva Europa cristiana pueden considerarse como una sola nación"76, o dicho más explícitamente aun:

Los pueblos cristianos europeos constituyen en esencia sólo un pueblo, reconocen la Europa común como su única patria verdadera y, de un extremo al otro de Europa, buscan y son atraídos aproximadamente por lo mismo. Buscan la libertad personal, el derecho y la ley, que es igual para todos y que, sin excepción ni prebenda, protege a todos. Buscan, mediante el trabajo y el esfuerzo, la oportunidad de ganar su medio de sustento seguro. Buscan la libertad religiosa en sus confesiones, la libertad de pensar según sus principios religiosos y científicos, y de expresarse y juzgar de acuerdo con ellos 77 .

Sin duda esta visión de la Europa medieval como armónico crisol de pueblos-naciones bajo el común denominador del cristianismo y el ius gentium recuerda aquellas líneas de Novalis: "eran unos tiempos bellos y esplendorosos aquellos en que Europa era una tierra cristiana, en que una sola cristiandad habitaba en esta parte del mundo conformada humanamente, en que un solo interés común reunía las provincias más distantes de este extenso imperio espiritual"78. Pero el parecido no va más allá de subrayar ambos la raíz unitaria de

\footnotetext{
72 gHS (GA, I/7, 93).

$73 \mathrm{gHS}(\mathrm{GA}, \mathrm{I} / 7,94)$

$74 \mathrm{GgZ}(\mathrm{GA}, \mathrm{I} / 8,349)$.

$75 \mathrm{GgZ}(\mathrm{GA}, \mathrm{I} / 8,350)$.

$76 \mathrm{gHS}(\mathrm{GA}, \mathrm{I} / 7,92-93)$.

$77 \mathrm{GgZ}(\mathrm{GA}, \mathrm{I} / 8,358)$.

78 Novalis, Cristenheit oder Europa (Schriften, WBG, vol. 2, p. 732). El opúsculo de Novalis fue compuesto y leído en el círculo romántico de Jena en otoño de 1799: ante la disparidad de opiniones sobre la conveniencia de publicarlo en la revista Athäneum -dado el catolicismo medievalizante que lo
} 
Europa en el Medievo. Frente a las ensoñaciones místico-religiosas de Novalis, la interpretación fichteana opera en los estrictos límites de la teología política. Fichte subraya, en efecto, el elemento "tensional" inherente a la configuración sociopolítica medieval: interacción de fuerzas centrífugas - libertad germánica de clanes y pueblos- y centrípetas -humanismo y cosmopolitismo cristianos, autoridad imperial y eclesial. Tensión que había de generar necesariamente una historia de discordias y enfrentamientos violentos por el dominio del espacio común así estructurado, es decir, por alcanzar la hegemonía continental. Y, en efecto, aquí hay que recordar el otro importante legado de la antigüedad:

con la introducción del derecho romano, al trasladarse el concepto romano de los imperatores a los modernos reyes y emperadores [...], entraron en vigor propiamente los conceptos políticos e instituciones [...]; así surgió primero en Francia una monarquía a la manera antigua y justo entonces se fueron separando los distintos pueblos por su constitución estatal79.

A su vez, la reforma luterana destruyó la autoridad espiritual de la Iglesia como marco unificador ${ }^{80}$, con lo cual la exigencia de unidad "ideal" del imperio cristiano se terminó de desplazar de facto al interior de esas nuevas monarquías: "cada Estado tiende a la monarquía universal cristiana o, cuanto menos, a tener la capacidad de tender a ella" 81 . Y como esta tendencia se desarrolla en relación a otros Estados cristianos que buscan lo mismo, aparece un verdadero "impulso expansivo" (Vergrösserungstrieb) 82 como motor interno de cada uno, que no puede tener otro fin que obtener la hegemonía absoluta sobre el conjunto de Europa. Si a ello añadimos el factor económico que, con la competencia nacional y los enfrentamientos coloniales, tiende a que "un Estado se apodere del comercio mundial" 83 , el resultado no puede ser otro que "una guerra inacabable de todos contra todos en el ámbito del comercio entre compradores y vendedores" 84 . De aquí que, al parecer de Fichte, la situación final de la Europa moderna no es otra que la de un estado de naturaleza (jurídico y económico) que, si bien se asienta sobre una matriz común -la república cristiana de los pueblos europeos-, parece incapaz de realizar su unidad si no es por la imposición violenta de un Estado sobre otro, aunque ello sea a costa de anular la reciprocidad que la constituye. El imperio napoleónico y su guerra total son el último episodio y más sangriento de esta tendencia a la monarquía universal. Frente a tal intento de uniformización y dominio, si -como se leía en el pasaje de 1796- hay que "garantizar la perduración de los Estados e incluso de cada uno en particular", habrá que repensar y reivindicar el componente plural y diversificador del crisol medieval: la pluralidad fáctica de los pueblos y naciones en cuanto sendas manifestaciones de una Europa en reciprocidad.

caracteriza-, se pidió el arbitrio de Goethe, que aconsejó no hacerlo. Fichte podría haber tenido noticia del ensayo por comentario oral o por los resúmenes incorporados por F. Schlegel y Tieck en su edición póstuma (1802-1805) de las obras de Novalis.

79 gHS (GA, I/7, 93-94).

80 gHS (GA, I/7, 94), GgZ (GA, I/8, 354).

${ }^{81} \mathrm{GgZ}(\mathrm{GA}, \mathrm{I} / 8,357)$.

$82 \mathrm{GgZ}(\mathrm{GA}, \mathrm{I} / 8,356)$.

$83 \mathrm{GgZ}(\mathrm{GA}, \mathrm{I} / 8,358)$.

$84 \mathrm{gHS}(\mathrm{GA}, \mathrm{I} / 7,98)$. 


\section{La diferencia nacional: la dualidad Francia-Alemania}

Kant ya había señalado que todo imperio universal, al propiciar el paternalismo del soberano y el hedonismo de sus ciudadanos, lleva necesariamente al despotismo ${ }^{85}$, de modo que las relaciones internacionales no han de regirse tanto por "la idea positiva de una república mundial (Weltrepublik)" 86 cuanto por la idea más modesta de una "federación de pueblos" (Völkerbund) ${ }^{87}$. Ahora bien, es una cuestión jurídicamente (a priori) indeterminada qué y cuáles sean los pueblos dispuestos para federarse. Definir tal noción en el ámbito europeo y articular su función hic et nunc -frente al imperialismo napoleónico- es el eje de la reflexión fichteana en los textos posteriores a 1806. Como ha expresado Marcuzzi, "el recorrido de Fichte aquí sería el haber sintetizado totalmente las dos unidades, la del pueblo y la del Estado, dando una teoría genética de su nexo, [...mientras que] Kant neutraliza la cuestión de la determinación concreta del pueblo para regular la cuestión de la formación de una buena constitución política"88.

Fichte trata, pues, de comprender lo "plural" de una Europa cuya unidad, por su carácter de reciprocidad, no puede someterse al dominio de una monarquía despótica. Ello significa que sus pueblos o naciones no son meras síntesis de individuos dispersos susceptibles de agregarse arbitrariamente en cualquier Estado, sino que configuran en si mismas totalidades de sentido previas a su institucionalización y articulación políticas, cuyos caracteres "naturales" (nativos, nacionales) remiten a su génesis histórico-cultural. En los términos del segundo período de la Doctrina de la Ciencia, Fichte subraya ahora cómo lo absoluto-divino se expresa necesariamente en una diversidad de formas colectivas:

La primera ley fundamental de la manifestación como tal [...] es que se fragmenta en una multiplicidad que, en cierto aspecto, es un todo infinito y, en otro, un todo clausurado. En este todo clausurado de multiplicidad cada individuo está determinado por todos los otros $\mathrm{y}$, a su vez, estos otros están determinados por ese individuo ${ }^{89}$.

Siendo cada pueblo una de estas pluralidades "cerradas" en que se materializan las estructuras intersubjetivas de la conciencia, cada uno constituye una "entidad" que goza de valor propio e irreductible a los demás: concepción que remite claramente al pluralismo cultural de Herder de raíz monadológica ${ }^{90}$. Pues bien, del mismo modo que las diversas percepciones de una mónada son resultado de una única "regla interna" que rige su despliegue, Fichte sostiene que "los primeros límites, originarios y verdaderamente naturales, de los Estados son, sin duda, los internos"91. ¿Cuál es este factor de unidad que define intrínsecamente cada pueblo? Dado que una comunidad se vertebra en torno a procesos de interacción

\footnotetext{
85 Kant, Mutmasslicher Anfang der Menschengeschichte (Ak, VIII, 121).

86 Kant, Zum ewigen Frieden (Ak, VIII, 357).

87 Kant, Metaphysik der Sitten. Rechtslehre (Ak, VI, 344).

88 M. Marcuzzi, Op. Cit., p. 383.

89 RDN (GA, I/10, 192).

90 I. Radrizzani, "Ist Fichtes Modell des Kosmopolitismus pluralistisch?" en Fichte-Studien, vol. 2, 1990 , p. 11

91 RDN (GA, I/10, 267).
} 
comunicativa y la comunicación tiene lugar primariamente a través del lenguaje, éste es el elemento determinante de las manifestaciones culturales y espirituales de un pueblo, pues "más bien los hombres son formados por la lengua que la lengua por los hombres"92. En efecto, una lengua es una configuración de la fonación cuyos sonidos se asocian primero a lo sensible-inmediato (sensaciones y sentimientos) y después, por el poder simbólico de tales signos, se transfieren a lo suprasensible 93 . De este modo, toda experiencia y comprensión de lo real está siempre mediatizada por ese sistema fonético y su capacidad imaginativo-metafórica. La lengua es así la regla interna que determina los productos espirituales de un pueblo y lo define en su especificidad:

Si se llama pueblo a unos hombres que se encuentran bajo las mismas influencias externas de su órgano de fonación y que conviven y configuran su lengua a través de un proceso de comunicación continuada, entonces hay que decir que la lengua de este pueblo es necesariamente tal como es y que, propiamente, no se trata de que este pueblo exprese sus conocimientos [en esta lengua], sino que sus conocimientos mismos se expresan en él [por la lengua] ${ }^{94}$.

Al establecer esta vinculación entre lengua, estructura de pensamiento y comprensión del mundo, Fichte se sitúa en el horizonte intelectual del movimiento romántico, pero sólo parcialmente. W. von Humboldt, denominando "visión del mundo" (Weltansicht) a cada una de estas formas de totalización, subrayará -en la línea de Herder- su carácter empírico-material susceptible de descripción en términos de antropología cultural ${ }^{95}$. Fr. Schlegel, basándose en la diferencia morfológica entre las lenguas flexivas (indoeuropeas) y las aditivas, distinguirá una experiencia del mundo dinámico-orgánica frente a una meramente compositivo-mecánica, lo que le permitirá establecer una jerarquía de pueblos en función de la superioridad expresiva de las primeras 96 . En cambio, el análisis fichteano, aunque también haga uso de consideraciones culturales o gramaticales, depende fundamentalmente-como indicamos antes- de un supuesto filosófico, a saber, que, por el proceder necesario de la imaginación productora, hay sólo dos modos de configurar la realidad: o bien una esquematización en términos de pasividad (substancia) que sólo permite operar con con-

92 RDN (GA, I/10, 145).

93 RDN (GA, I/10, 146-148).

$94 \mathrm{RDN}(\mathrm{GA}, \mathrm{I} / 10,146)$.

95 Para comparar la concepción del lenguaje y de la nación en Humboldt y Fichte véase: J. Hennigfeld, "Fichte und Humboldt - Zur Frage der Nationalsprache" en Fichte-Studien, vol. 2, 1990. Terminológicamente hay que subrayar que el uso que hace Fichte de la expresión "visiones del mundo" (Ansichten der Welt) no coincide exactamente con el de Humboldt. Para éste constituyen una pluralidad analizable por mera observación antropológico-cultural. Para Fichte dependen de una tipología cerrada y transcendentalmente deducible, de modo que oscilan necesariamente entre dos polos, las determinadas por la configuración sensible del mundo y las que, elevándose por encima de la sensibilidad, se fundan en la actividad libre (véase al respecto la lección $\mathrm{V}$ de La exhortación a la vida bienaventurada).

96 "Las lenguas flexivas suponen un a priori espiritualmente activo que crea la lengua como un 'acuerdo' de la comunidad, mientras que las lenguas aditivas, originariamente receptivas, de entrada son fundamentalmente imitativas de datos empíricos naturales, ya se trate de percepciones externas (Leibniz) o de totalidades afectivas (Rousseau)" (A. Stanguennec, La philosophie romantique allemande, París, Vrin, 2011, p. 103). 
ceptos fijos y estáticos produciendo una inteligencia prisionera de formulismos y de objetos; o bien una en términos de actividad (libertad, deber) que se abre a un pensamiento fluido y dinámico, capaz de intuir el curso de la vida espiritual. Al darse dos operaciones transcendentales como condición de posibilidad de cualquier visión del mundo, Fichte se aleja claramente del pluralismo cultural de Herder-Humboldt. Pero también se distingue, a pesar de su mayor afinidad ${ }^{97}$, de la posición de Schlegel pues es el nivel transcendental (a priori) y no el lingüístico-morfológico - al fin y al cabo, todavía fáctico- el que determina las estructuras categoriales de la experiencia del mundo 98 . Pues bien, igual que estas dos posibilidades operaban ya en los pueblos antiguos (Asia, Grecia-Roma), reaparecen, con las modificaciones culturales pertinentes, entre los modernos y determinan la tipología de sus “naciones". Veámoslo.

Mientras unos clanes germánicos permanecieron en su territorio y conservaron su lengua propia, otros se desplazaron a las tierras interiores del imperio y se sometieron a una romanización completa99. El caso paradigmático de los segundos es, para Fichte, el de los francos 100: ocupando una de "las más bellas provincias del imperio romano [...], con el tiempo obtuvieron para su disfrute todo el resto, tanto el cristianismo y las letras como la lengua, sus propiedades y las artes"101. Con el abandono de su dialecto germánico por el latín, se produjo un cambio substantivo: el pueblo perdió la continuidad con la base lingüística propia -su "raíz vivificadora"102 - y adoptó una lengua ya elaborada y fijada terminológicamente sin haber participado activamente en los procesos internos de génesis de sentido. Por el contrario, los germanos autóctonos, manteniéndose en su territorio y lengua, preservaron la fuente interna de su espíritu creador. Al no entrar en posesión de una cultura abstracta y sofisticada y diluirse en ella, el alemán siguió siendo un "pueblo originario" (Urvolk). "Originario" en cuanto "enraizado" en "una lengua viva hasta sus primeras emanaciones a partir de la fuerza de la naturaleza [...] como sucede con la lengua griega" 103 , que

\footnotetext{
97 Fr. Schlegel publicó sus tesis en el Ensayo sobre la lengua y la filosofía de los hindúes en 1808, el mismo año que Fichte sus Discursos. La proximidad de posiciones, pues, no se debe tanto a una influencia directa entre ambos textos cuanto a que el pensamiento de Schlegel arranca de un conocimiento y discusión de la Doctrina de la Ciencia de Jena.

98 En expresión de E. Balibar: "Fichte ignora por completo este punto de vista genético [prioridad de la lengua germánica o más bien de la indo-germánica], del mismo modo que ignora la realidad lingüística y en particular la gramática, que no tiene nada que ver con su problema" ("Fichte et la frontière intérieure. À propos des Discours à la nation allemande" en La crainte des masses. Politique et philosophie avant et après Marx, Paris, Galilée, 1997; traducción española, "Fichte y la frontera interior. A propósito de los Discursos a la Nación Alenana", p. 20, en www.latorredelvirrey.es/pdf/10/ etiennebalibar.pdf).

99 RDN (GA, I/10, 144).

100 El resto de pueblos germánicos romanizados son simplemente omitidos por Fichte, pues carecerían de una mínima unidad interna que rigiera su desarrollo: "Diferente es para los otros [pueblos neolatinos] por tratarse de otra historia. Los españoles, desposeídos y sometidos. Los italianos, nunca han sino unidad. Los ingleses, historia variada y sucesión de pueblos dominantes. En absoluto pueden considerarse a partir de un principio tan simple como los otros" (StaL; GA, II/16, 56).

$101 \mathrm{StaL}(\mathrm{GA}, \mathrm{II} / 16$ 55).

102 RDN (GA, I/10, 151).

103 RDN (GA, I/10, 154).
} 
así le dispone para "la actividad viva del pensamiento"104. Aunque también "originario" en cuanto "primitivo", pues su rasgo peculiar "a diferencia de las otras naciones europeas consiste en la capacidad y receptividad para la formación"105. El alemán es así un pueblo que aún ha de ser educado, pero, dada la fuerza viva de su lengua originaria, tal educación, lejos de ser recepción pasiva de una terminología ajena -como en el caso de las culturas neolatinas-, permitirá formarse y crearse en el "espíritu" capaz de transcender la letra muerta.

A esta caracterización de lo francés y lo germánico, Fichte añade los tópicos dieciochescos sobre el carácter de los pueblos 106: oposición entre formación espiritual y vida en los franceses, plena compenetración de ambas en los alemanes; educación como mero juego de ingenio en los primeros, seriedad y profundidad en los segundos; carácter voluble y superficial de aquéllos, diligencia y esfuerzo de éstos. En suma, el carácter nacional francés -"rico de ingenio, amable, buen padre, buen señor, buen servidor, etc."107- no hace más que mostrar la aurea mediocritas de quienes se adaptaron perfectamente a la naturaleza benigna y al orden romano-cristiano de la "provincia" por excelencia. En cambio, el pueblo alemán, anclado en su independencia y autenticidad vitales, más bien se caracteriza por tener una "historia negativa"108 respecto a la romanidad: reacio a cualquier forma de unidad política centralizada, frente a la tendencia monárquica inherente a Francia109; y opuesto radicalmente al cristianismo institucionalizado católico-romano, pues "[con la Reforma] no se trataba sólo de cambiar el mediador externo entre Dios y los hombres, sino de no necesitar en absoluto ningún mediador externo"110. Caracteres nacionales a los que Fichte suma las hipérboles más extremas para destacar la especificidad de lo alemán: "sólo una lengua viva puede tener poesía verdadera; [...] una lengua muerta no puede tener poesía en ese sentido superior"111, "sólo el alemán -el hombre originario [...]- tiene verdaderamente un pueblo"112, "sólo el alemán es capaz de amor verdadero y racional a su nación"113, "si os [los alemanes] hundís, se hunde con vosotros toda la humanidad sin esperanza de recuperación alguna"114, "si el alemán no salva la situación cultural de la humanidad, no la salvará ninguna otra nación europea"115.

Más allá de los excesos retóricos de tales pasajes -excusables si se considera que están compuestos en el fragor del combate contra el invasor napoleónico116-, la línea argumenta-

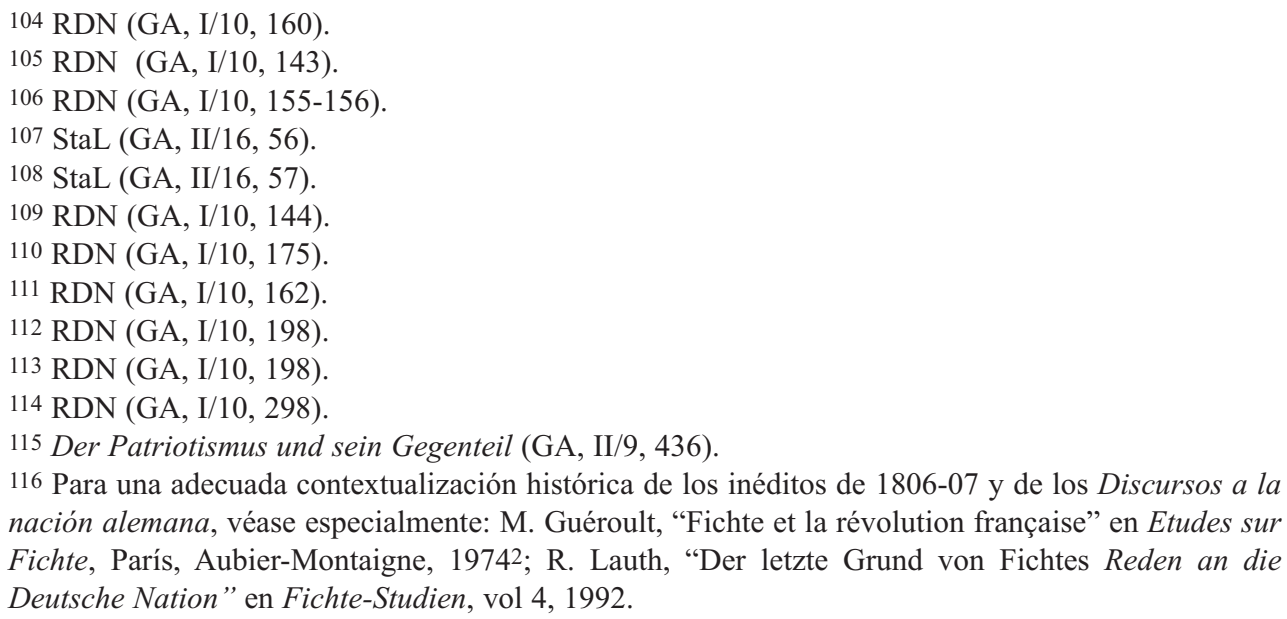


tiva central de Fichte persigue otro objetivo. El elemento germánico de la Europa moderna (tanto francés como alemán) se sobrepone y define (en un sentido u otro) respecto a su relación dialógico-cultural con el sustrato antiguo: en términos técnicos de la Doctrina de la Ciencia, lo que constituye el "fundamento de diferencia" (Unterscheidungsgrund) entre ambos pueblos es a la vez su "fundamento de relación" (Beziehungsgrund). Es decir, Francia y Alemania son dos modos diferentes pero interrelacionados de una común vinculación al legado grecolatino:

En cierto modo, las dos partes de la nación común son una sola y, tan sólo en esta separación y unidad conjuntamente, son un injerto en el tronco de la formación antigua que, sin esto, se hubiera interrumpido en los nuevos tiempos y la humanidad habría tenido que empezar de nuevo su camino. Pues bien, dadas sus destinaciones -diferentes en el punto de partida pero convergentes en su objetivo-, ambas partes se han de reconocer cada una a si misma y a la otra, y se han de utilizar una por medio de la otra. Especialmente, cada una ha de permitir que la otra se mantenga y desarrolle en su genuina especificidad para que la formación universal y completa del todo avance adecuadamente117.

Esta diferente relación con el sustrato antiguo común admite una lectura en clave de proceso de apropiación y recreación dialógico-culturales: si se quiere, una versión tardía del debate sobre los antiguos y los modernos ${ }^{118}$. Efectivamente, la Europa moderna puede entenderse como resultado de dos modos de interpretación y comprensión de su tradición constitutiva (filosofía griega, derecho romano, cristianismo). O bien se atiende al aspecto fijado terminológicamente del pensamiento en un sistema "ya dado" que nos limitamos a reproducir, o bien se reviven las donaciones de sentido originales generándose un pensamiento que, reformulando activamente el pasado, se construye dinámicamente a sí mismo como proceso autoformativo continuado. La primera posibilidad caería del lado de las lenguas neolatinas, ejemplificadas en la cultura francesa; la segunda correspondería a las virtualidades autogeneradoras de la lengua alemana, recién convertida en lengua de cultura propiamente dicha119. Ambas opciones son divergentes pero, en su diferencia, se iluminan mutuamente y reactualizan a su modo la herencia compartida. Por tanto, Francia y Alemania -o Europa como reciprocidad resultante- se constituyen a través del diálogo entre una doble alteridad: de cada nación respecto a la otra y de ambas respecto a los antiguos. Diálogo formativo por excelencia, pues no sólo se trata de un ejercicio de intersubjetividad contemporánea, sino transepocal:

117 RDN (GA, I/10, 168).

118 M. Fumaroli (La Querelle des Anciens et des Modernes, París, Gallimard, 2001, p. 214) apunta cómo tal querella, a través de la cuestión homérica, se traslada a Alemania. Allí, después de Wieland y el clasicismo de Weimar, la polémica es reactivada por las Cartas sobre educación estética del hombre de Schiller, de donde pasa a Hölderlin y se refleja también en este punto de los Discursos de Fichte.

119 Téngase presente, no sólo las traducciones de los trágicos por Wieland o la nuevas versiones transgresoras de Hölderlin, sino la reactualización de los temas y el espíritu de la tragedia antigua en Goethe o Schiller. Recuérdese el ensayo ya clásico de J. Taminiaux, La nostalgie de la Grèce a l'aube de l'idéalisme alémand, La Haya, Nijhoff, 1967. 
Para desarrollar la fuerza del espíritu en su sentido más universal, nosotros los modernos no tenemos nada más adecuado que el aprendizaje de las lenguas clásicas [...]. ¿Cómo el alumno, por encima de la niebla de palabras que él no ha creado y, por tanto, no entiende -niebla que hace surgir el espíritu que inconscientemente fluctúa en el lenguaje- $[\ldots]$ ha de alcanzar la intuición vivificante de la cosa misma? Considero que ello sólo puede suceder mediante el estudio de las lenguas cuya configuración conceptual diverge completamente de la modernidad, que obliga decididamente a cada uno, que en esta región ha de llegar hasta la comprensión auténtica [...], a elevarse más allá de los signos hacia algo superior al signo lingüístico, al concepto de la cosa. Estudio que, precisamente por esto, no es substituible por el aprendizaje de ninguna lengua moderna 120 .

Con esta contraposición dialógico-formativa la modernidad europea explicita al máximo la alternativa ya aparecida rudimentariamente en el mundo antiguo: por un lado Francia, es decir, las reificaciones lingüísticas y teórico-prácticas asociadas al derecho romano y su tendencia a la monarquía universal, mediatizadas por el catolicismo; por otro Alemania, esto es, la lengua viva y la actividad pura que transciende toda limitación objetual y aspira a realizar los ideales últimos de la libertad y del auténtico cristianismo luterano. El ámbito generado por la tensión entre ambas perspectivas, en cuanto que asimilación de lo antiguo, construcción del presente y a la vez proyecto de futuro, determina la "gran república europea de Estados". Diálogo inter-nacional que, para Fichte, alcanza su expresión simbólica en la relación que se establece entre la revolución de 1789 y la misma Doctrina de la Ciencia: "mi sistema es el primer sistema de la libertad; igual que aquella nación [Francia] quebró las cadenas políticas del hombre, mi sistema lo liberó, en la teoría, de las cadenas de la cosa en sí [...]; en los años durante los cuales la nación luchaba por su libertad, surgió mi sistema"121. Veamos qué implica tal vinculación para la comprensión de Europa.

La Doctrina de la Ciencia "ha de consistir y no puede consistir más que en alcanzar un esquema del espíritu humano en general"122. Y como el espíritu humano no es "ningún ser, ningún subsistir [...], sino que es actuar y nada más -ni tan sólo puede denominarse algo activo-"123, su captación filosófica transciende todas las posibles formulaciones conceptuales que puedan emplearse para expresarlo. Es decir, la filosofía, lejos de quedar apresada por las determinaciones lingüísticas, ha de hacer un uso vivo y dinámico de la lengua, pues "una terminología fijada [es] el medio más cómodo de los amantes de la letra para privar a un sistema de su espíritu y convertirlo en un esqueleto reseco"124. Existe así una íntima afinidad entre la tarea filosófico-transcendental y la lengua alemana en que se expresa. Así, no sólo es comprensible que "la nación que descubriera esta ciencia le diera su nombre [Wissenschaftslehre] en su lengua"125, sino que Fichte, llevando la afinidad al límite, puede sostener que "esta filosofía es propiamente sólo alemana, esto es, originaria; y, a la inversa, si alguien llegase a ser un verdadero alemán, no podría filosofar de otra manera"126.

\footnotetext{
120 Aphorismen über Erziehung (GA, II/7, 17-18).

121 Fichte a Bagessen, ?.4.1795 (GA, III/2, 300).

122 Vorlesungen über Geist und Buchstabe in der Philosophie (GA, II/3, 328).

123 Erste Einleitung in die Wissenschaftslehre (GA, I/4, 200).

124 Grundlagen der gesamten Wissenschaftslehre (GA, I/2, 252).

125 Über den Begriff der Wissenschaftslehre (GA, I/2, 118).

126 RDN (GA, I/10, 185).
} 
El aparente exceso "nacionalista" de la última afirmación es matizado por otra connotación en juego. La Doctrina de la Ciencia permite demostrar apodícticamente las exigencias universales y necesarias derivadas de la racionalidad para toda conciencia posible y en todos los ámbitos de realidad (conocimiento, derecho, moral, religión). Por consiguiente, su validez, lejos de quedar restringida al pueblo particular que la ha descubierto, tiene un valor científico-universal, pues con ella la humanidad ha alcanzado la plena conciencia de sí misma como actividad libre que subyace a toda objetividad, es decir, ha abandonado la forma inmediata de esquematización sensible para elevarse a la actividad productiva misma de la subjetividad. Por tanto, la aportación filosófico-científica "alemana", aunque haya sido facilitada por los rasgos estructurales de su lengua, supera su significado nacional-particular - psicología de un pueblo frente a otros- y expresa una adquisición de vocación universal. En este sentido, "alemán" puede adjetivar a todo hombre que se haya elevado a la actividad de la razón y la libertad, con independencia de su pertenencia nacional-lingüística particular:

El auténtico fundamento diferenciador [de lo alemán] radica en si alguien cree en algo absolutamente primero y originario en el hombre mismo, en la libertad, en la mejora infinita de nuestra especie, o no cree en nada de esto [...]. Quien cree en la espiritualidad y la libertad de esta espiritualidad y quiere el avance eterno de esta espiritualidad mediante la libertad -haya nacido donde sea y cualquiera que sea la lengua que hable- es de nuestra clase, nos pertenece y tiene que ver con nosotros. Quien cree en el reposo, el retroceso o la danza circular, o pone una naturaleza muerta al timón del gobierno del mundo -haya nacido donde sea y cualquiera que sea la lengua que hable- es no-alemán y ajeno a nosotros, siendo de desear que se aleje completamente de nosotros cuanto antes mejor ${ }^{127}$.

Así pues, la comprensión del pueblo alemán en la Europa contemporánea combina un doble significado en el texto fichteano: el "nacional-particular" como herencia de la lengua y carácter originarios de los pueblos germanos autóctonos, frente a la asimilación externa de lo romano-cristiano por los pueblos neolatinos; y el "nacional-universal" como pueblo en que se ha vehiculizado lingüísticamente la filosofía transcendental, única capaz de conducir la humanidad a sus últimas metas racional-morales, jurídicas y políticas. En palabras de Balibar, la contraposición entre la "nación empírica" y la "nación transcendental"128. En el segundo sentido, Alemania está llamada a realizar, por medio de una formación basada en la nueva filosofía, aquel "reino de la libertad" por el que la nación francesa combatió en su revolución pero que, con Napoleón, ha sido incapaz de lograr129. Expresándolo en términos de patriotismo:

El patriota quiere que el fin del género humano se alcance de entrada en aquella nación de la que él mismo es miembro. En nuestra época, tal fin sólo puede ser promovido por la ciencia. Por tanto, la ciencia y su máxima extensión posible en este momento es el fin más inmediato del género humano, y la humanidad no puede poner ni admitir ningún otro fin más que éste. El patriota ale-

127 RDN (GA, I/10, 195-196).

128 E. Balibar, Op. cit., trad. esp, p. 23.

$129 \mathrm{StaL}(\mathrm{GA}, \mathrm{II} / 16,62)$. 
mán, en especial, quiere que este fin se alcance de entrada entre los alemanes y que, a partir de ellos, extienda su consecución sobre todo el resto de humanidad 130 .

Que "lo alemán" se caracterice por esta vocación de universalidad capaz de incorporar y superar las aportaciones francesas y dotarlas de toda su fuerza, tiene dos confirmaciones relevantes. (1) Como señala Lauth131, la intención de "fundir el antiguo concepto nacional alemán con el francés-revolucionario en una nueva unidad” obliga a Fichte, paradójicamente, a emplear el término latino Nation para dejar claro que no se trata de apelar a la mera "naturalidad" del Volk (Herder), ni a su idiosincrasia cosmovisional (Humboldt), sino de defender los principios político-jurídicos de la revolución (nation republicana, en sentido francés) ${ }^{132}$. (2) Una simple ojeada al proyecto fichteano para la "educación nacional de los alemanes", esbozado en los capítulos 9-10 de los Discursos, permite constatar como, a excepción del carácter vehicular de la lengua alemana y la apelación a la pedagogía activa de Pestalozzi, el resto de propuestas no tienen nada de "nacionales" -algunas incluso están inspiradas literalmente en la escuela pública francesa creada en el período del Consulado (1799-1804): traspasar las instituciones educativas de manos eclesiásticas al Estado, educación común y conjunta para ambos sexos, cultivar tanto las capacidades intelectuales como corporales (trabajos manuales, gimnasia), instrucción cívica y religiosa para despertar el sentido moral, vincular la nación a la humanidad, etc.

En la comprensión de Fichte, pues, la nación alemana, a través de su diálogo con Francia y del valor universal de la Doctrina de la Ciencia, encarna la configuración del mundo por la razón y la libertad. El combate entre la visión del mundo según el modelo de la substancia (dogmatismo) y el de la actividad (idealismo), iniciado históricamente con la contraposición entre lo asiático y lo europeo, se resuelve finalmente, con Alemania, a favor del segundo. Y en este proceso tiene lugar una transformación paralela: lo alemán-particular-herencia germánica originaria- se transmuta en un alemán-universal que, "haya nacido donde sea y cualquiera que sea la lengua que hable", se define exclusivamente por defender de los ideales racionales, no ya sólo de la "humanidad europea" sino de la humanidad en general133. Se comprende así porqué, como constatábamos más arriba, la comprensión de lo nacional en Fichte tenía en su base la distinción filosófica entre las dos formas de esquematización de la imaginación transcendental, en lugar de limitarse a ser una constatación empírica de tipo cultural (Humboldt) o gramatical-morfológica (Schlegel).

Este horizonte político republicano y formativo universalista es el que ha de impregnar el verdadero patriotismo alemán, opuesto radicalmente a "aquel concepto oscuro y erróneo

130 Der Patriotismus und sein Gegenteil (GA, II/9, 404).

131 R. Lauth, Op. Cit., pp.216-217.

132 Para los diversos sentidos que incluye el uso fichteano de "nación" aplicado a Alemania, véase: J. Rivera, Op. cit., pp. 330-333.

133 Es significativa la influencia -en especial, respecto a las cuestiones de filosofía práctica- que pudo tener en Husserl su aproximación a Fichte en las conferencias impartidas a los oficiales convalecientes de la I Guerra Mundial: Fichtes Menschheitsideal. Drei Vorlesungen von 1917 (Husserliana, vol. XXV). Y si Husserl acabará calificando al filósofo como "funcionario de la humanidad", Fichte se considera a si mismo "sacerdote de la ciencia" (Über das Wesen der Gelehrten; GA, I/8, 131). 
de un patriotismo particular prusiano, engendro de la mentira y de la lisonja más torpe"134. En última instancia, pues, el nacionalismo de Fichte "era ciertamente un nacionalismo 'con intención cosmopolita', ya que con la elevación (interior) de la nación alemana Fichte conecta la intención 'de elevar, con ella, a los todos pueblos restantes a la vez"135. Tesis expresada así por el filósofo:

En lo relativo a la legalidad, [el hombre completamente formado] consagra todas sus fuerzas a su Estado, a su ciudad, a su cargo, a aquel pedazo de tierra donde habita ahora, aunque se siente encaminado al todo. En su ánimo el amor a la patria y el sentido cosmopolita van íntimamente unidos y guardan entre si una relación estrecha. El amor a la patria es su acción, el sentido cosmopolita su pensamiento; el primero es el fenómeno y el segundo el espíritu interno de este fenómeno, aquello invisible en lo visible136.

Ahora bien, es preciso reconocer que el uso del término Deutsch con dos sentidos tan dispares, el histórico-particular de lo germánico y su significación científico-universal -"lo alemán" frente a lo francés y a la vez como superación cosmopolita de la oposición-, produce cuando menos una equivocidad léxica de connotaciones no desdeñables ${ }^{137}$, aunque fueran ciertamente imprevisibles para el autor: consecuencia, en última instancia, de asociar en diversas ocasiones las dos esquematizaciones transcendentales a dos lenguas-culturas nacionales determinadas. Prueba de tales ambigüedades son las lecturas divergentes que la posteridad inmediata hará del pensamiento político de Fichte y que pasan por posiciones tan dispares como las liberales, democrático-radicales, socialistas y también nacional-conservadoras ${ }^{138}$. Por otro lado, aun admitiendo que lo "auténticamente alemán" consista en optar por una filosofía basada en la actividad universalista de la razón - es decir, en la Doctrina de la Ciencia139- y que lo no-alemán se emplee polémicamente contra "aquella filosofía mortuoria del ser, que ciertamente se convierte en filosofía de la naturaleza, la más muerta de todas las filosofías"140, tales pronunciamientos están haciendo al menos de Schelling el caso prototípico de "no-alemán y ajeno a nosotros, siendo de desear que se aleje completamente de nosotros": en lo cual no deja de estar latente (vollens nollens) aquel germen ultraconser-

134 Der Patriotismus und sein Gegenteil (GA, II/9, 404).

135 H.J. Becker, Op. cit., p. 150.

136 Philosophie der Mauererei. Briefe an Konstant (GA, I/8, 450).

137 Demasiado unilaterial es, a mi parecer, la interpretación de J.Ch. Goddard, donde la dimensión activo-universal parece ser el único sentido "propio" de lo alemán: J.Ch. Goddard, "Fichte est-il réactionnaire ou révolutionnaire?" en Fichte et la politique, J.Ch. Goddard y J. Rivera, edts., Milán, Polimetrica, 2008, p. 483-501; "Fihte, ili stalna domorodačka revolucija", Theoria, Beograd, 2012, vol. 55, p. 45-53 (trad. francesa, "Fichte ou la révoution aborigène permanente, en www.europhilosophie.eu/mundus/IMG/pdf/

Fichte._Revolution_aborigene.pdf).

138 E.Fuchs, "Tracce del pensiero fichtiano nel movimiento nazionale tedesco (1819-71)" en Filosofia transcendentale e destinazione ètica, Nápoles, Guirini e Associati, 1995.

139 En otras palabras, que "ser alemán signifique propiamente ser fichteano, que formarse para la alemanidad signifique adherirse al criticismo y que la verdadera nación del buen patriota sea la ciencia supranacional" (I. Radrizzani, Op. cit., p. 19).

140 RDN (GA, I/120, 197). 
vador dispuesto a marginar de la cosa pública al "enemigo interior", al menos como Kulturkampf contra todo cuanto difiera de la raíz originaria de la Alemania germánica y luterana.

Tal deriva nacional ultraconservadora, en función de la propia comprensión fichteana, sería inherente a todo pueblo europeo que deje de pensarse en la red de reciprocidades lingüísticas y culturales que le dan identidad como uno de los diversos interlocutores que forman "la nación común". Es decir, los pueblos europeos sólo pueden entenderse adecuadamente a sí mismos si, más allá de su particularismo, se reconocen en la vertebración dialógica que los constituye en el horizonte histórico heredado del cosmopolitismo (jurídico y político) romano-cristiano, reconstruido transcendentalmente por la Doctrina de la Ciencia. ¿Cuál debe ser, por tanto, la vertebración política europea capaz de conjurar el peligro nacional-conservador y realizar los ideales del derecho de gentes?

\section{La vertebración política europea}

Desde 1806 la cuestión nacional es central para Fichte ya que, con la disolución del Imperio Germánico, "ha desaparecido el lugar donde los asuntos nacionales alemanes tenían su sede y se ponían bajo el timón del Estado"141. Las estrategias concretas para resolver la impotencia política de la fragmentada Alemania pueden variar: en 1808 los Discursos proponen diseñar una "educación nacional" como resistencia cultural al invasor napoleónico $^{142}$, mientras que en los cursos de 1813 se secunda la proclama del rey de Prusia a una guerra de liberación nacional ${ }^{143}$. Pero ambas estrategias se inscriben en una evaluación global de la situación europea, pues la verdadera ciencia política "no parte de un estado real completamente determinado, pues entonces no habría ninguna política general sino solo específica para Inglaterra, Francia, Prusia [...], sino de la situación común a todos los Estados de la gran república europea de la época"144.

La reflexión "geopolítica" de Fichte se despliega a partir de los elementos expuestos hasta aquí. Por un lado, el relativo equilibrio de fuerzas centrífugas y centrípetas de la Europa medieval se rompió con los modernos estados nacionales, cada uno de los cuales, si bien pretende establecer el ideal de la monarquía universal, lo ha hecho de manera despóti-

141 RDN (GA, I/10, 214).

142 "Si en alguna ocasión el linaje alemán tuviera que hundirse en la romanidad, hubiera sido mejor que esto pasara en la antigua que en la nueva. Nos alzamos contra aquélla y la vencimos, pero ahora habéis sido deshechos por ésta. Siendo así las cosas, no queráis ahora vencerlos con las armas corporales, sino que sólo vuestro espíritu ha de elevarse frente a ellos y mantenerse en pie. Se os ofrece el gran destino de fundar el imperio del espíritu y de la razón, aniquilando la violencia corporal bruta como señora del mundo. Si lo hacéis así seréis dignos de vuestro origen" (RDN; GA, I/10, 296).

143 "[La guerra verdadera] es la movilización de todas las fuerzas, lucha a vida o muerte, ninguna paz sin victoria completa, es decir, sin asegurarse completamente contra todo posible atentado a la libertad; ninguna consideración por la vida ni la propiedad, ningún cálculo sobre una paz futura [...]; entonces, el corazón del hombre ilustrado se ha de alzar al primer movimiento de su patria, ha de estar atento para tomarla seriamente" (StaL; GA, II/16, 49-50).

$144 \mathrm{gHS}(\mathrm{GA}, \mathrm{I} / 7,42)$. 
ca. Por otro lado, Francia, si bien con la revolución interrumpe brevemente tal proceso histórico, acaba renovándolo en grado superlativo. Su tendencia católico-romana a la autocracia, su lengua y mentalidad neolatinas y su cultivo lúdico e ingenioso del espíritu causaron que finalmente "la unanimidad sobre el derecho no fuera posible, de modo que -por su carácter nacional- cada opinión particular debía encontrar su partido y así -sin un poder protector- los partidos habían de extenuarse en sus luchas internas"145. En tal situación de desintegración política, Napoleón usurpa el poder traicionando la revolución, instaura un nuevo despotismo interior y, mediante una guerra que "saquea y devasta la tierra, pulverizándola en un caos sombrío"146, instaura un imperialismo exterior según un plan preconcebido:

A este fin inmediato puesto por la ley del mundo habría que sacrificar todo el bienestar de Europa, verter toda su sangre, pues para eso existe. Este gran plan del mundo, que ciertamente se extiende por encima del objetivo de una vida humana, debe proseguir y realizarse después de él por su dinastía, hasta que entre en escena, quizá un milenio más tarde, otro héroe inspirado como él [Napoleón] y, con una nueva revelación, se proponga continuar su creación y la de Carlomagno147.

El triunfo de la monarquía universal napoleónica significaría la imposición unilateral por las armas del principio nacional francés sobre el alemán, de las tendencias despóticas romanas sobre el impulso federativo germánico. Por tanto, el inicio de un despotismo universal. Ciertamente la vertebración política europea sólo puede consistir, para Fichte, en algún tipo de restauratio imperii, pero una restauración que garantice culturalmente las diferencias nacionales y políticamente el Estado de derecho. Su alusión a la unidad de la Europa carolingia tiene el valor simbólico de expresar aquella interrelación entre el sustrato romano, lo cristiano y lo germánico que determina internamente la historia europea desde el Medievo, a la vez que anticipa (proféticamente) cómo el porvenir inmediato de Europa se juega en la relación que se establezca entre las dos orillas del Rin. Pues bien, ¿qué instrumento político permitiría alcanzar una unidad en reciprocidad en lugar de una unifícación despótica del continente?

Tratándose de una cuestión "política" y no meramente apriórico-jurídica, se entiende que Fichte "tuviera que hacerse intensamente consciente del significado histórico determinante de los factores que definían la política de potencias"148. Dada la noción moderna de soberanía, los Estados europeos operan según la inercia del poder: como "cada Estado tiene derecho a autoconservarse como tal Estado" y tal conservación acarrea un incremento progresivo de costes, su existencia "sólo está garantizada por el incremento de su poder, por lo que $[. .$.$] tiende constantemente a conquistar y extenderse en su entorno"149. Antes de toda$ propuesta constructiva, habrá que reconocer lúcidamente que:

\footnotetext{
$145 \mathrm{StaL}(\mathrm{GA}, \mathrm{II} / 16,62)$.

$146 \mathrm{RDN}(\mathrm{GA}, \mathrm{I} / 10,275)$.

$147 \mathrm{StaL}(\mathrm{GA}, \mathrm{II} / 16,59)$.

148 R.Schottky, "Fichtes Nationalstaatsgedanke auf der Grundlage unveröffentlicher Manuskripte von 1807" en Fichte-Studien, vol. 2, 1990, p. 117.

149 Rechtslehre [RL] (GA, II/13, 291).
} 
en su relación con otros Estados no hay derecho ni ley -si no es el derecho del más fuerte-, de modo que aquí el derecho divino del destino y del gobierno del mundo deposita la responsabilidad en manos del príncipe y lo eleva por encima de los mandamientos de la moral individual a una esfera superior de costumbres, el contenido material de las cuales viene dado por la expresión Salus et decus populi suprema lex esto [la salvación y el honor del pueblo será la ley suprema] ${ }^{150 .}$

Esta dinámica expansiva de la soberanía estatal explica que los estadistas europeos, más allá de las declaraciones retóricas, hayan aplicado siempre a su política exterior aquellos consejos que Maquiavelo expresó con toda claridad ${ }^{151}$ : servirse de la menor ocasión para asegurar e incrementar la seguridad territorial del Estado y no confiar en la palabra de ningún soberano mientras no se lo pueda obligar coactivamente. Con ello, las naciones subsisten en un estado natural de guerra de todos contra todos, "pues nadie puede creerse que, pensando así los príncipes y actuando según las dos reglas anteriores, pueda tener fin la guerra en Europa"152. Pero como la idea de una coexistencia pacífica de los pueblos es uno de los elementos fundacionales de la cultura europea (ius gentium cristiano), los Estados también han intentado "regular" tal situación fáctica. La cuestión es si tal regulación puede ser resuelta por el mecanismo tradicional: como todos los soberanos intentan incrementar su poder hasta ser una amenaza para los demás, del temor recíproco resultará un estado de paz. Tal es el "conocido sistema de un equilibrio de poder en Europa"153, "fenómeno de la historia moderna europea como sucedáneo de una garantía [de paz]"154.

¿Puede ser esta doctrina del equilibrio de potencias el instrumento para vertebrar políticamente el continente? Fichte parece acariciar por un momento tal posibilidad. De acuerdo con los análisis anteriores, ello exigiría que al menos las dos grandes naciones europeas, Francia y Alemania, alcanzasen un equilibrio armado. Lo cual, a su vez, requeriría superar la fragmentación territorial y política del desaparecido Imperio Germánico y crear un gran Estado unificado centroeuropeo como contrapeso al que existe en la otra orilla del Rin. ¿Puede pensarse en tal posibilidad? Si no inmediatamente, al menos como proyecto o sueño para un futuro lejano merece ser tomada en consideración. Y efectivamente Fichte dedica los primeros meses de 1807 a exponer tal idea: son los borradores de la Constitución de los alemanes al inicio del siglo XXII. A pesar del carácter fragmentario del manuscrito, tal propuesta futurista es lo suficientemente detallada como para mostrar su idea directriz ${ }^{155}$ : el Estado alemán sólo podrá tener suficiente poder disuasorio para compensar el poder francés si se diseña según el modelo jacobino.

El nuevo Estado abarcaría todos los pueblos de lengua alemana, incluida Austria, y con la posible incorporación de los territorios polacos 156 . Desaparecida la soberanía tradicional de los príncipes dinásticos ${ }^{157}$, el Estado se articularía en divisiones provinciales geográficas

150 Über Macchiavelli (GA, I/9, 244-245).

151 Ibid. (GA, I/9, 242-243).

152 Ibid. (GA, I/9, 244).

$153 \mathrm{RDN}(\mathrm{GA}, \mathrm{I} / 10,269)$.

154 RL (GA, II/13, 292).

155 Para una exposición, contextualización y ponderada evaluación de las líneas maestras de este proyecto fichteano, véase: R.Schottky, $O p$. cit.

156 Die Republik der Deutschen (GA, II/10, 387-389).

157 Ibid. (GA, II/10, 409). 
y tendría la capital en su centro, Magdeburgo ${ }^{158}$. Su constitución sería republicana, con un Senado representativo de sus territorios y estamentos, y un ejecutivo presidido por un "protector"159. Conforme al espíritu universalista de la filosofía alemana, "el fin de nuestra legislación será $[\ldots]$ formar en todos sus aspectos la humanidad en la nación en el grado que lo disponga la época"160: de ahí el detalle con que se despliega el programa educativo de la escuela pública obligatoria en afinidad a los Discursos. Para dar la máxima coherencia y unidad al cuerpo social, aunque se respeten las tres iglesias cristianas tradicionales en Alemania (católica, luterana y evangélica), el Estado estará interesado en promover una cuarta confesión: "la auténtica religión civil y legítima del Estado", a saber, el "cristianismo universal [...] que reconoce como verdadera la doctrina de Dios del cristianismo porque y en la medida que puede descubrirse por la propia razón"161, cristianismo racional cuya descripción pormenorizada -incluido su culto civil- ocupa la parte más extensa del manuscrito. Ciertamente esta gran Alemania "habrá de ofrecer garantías a todos los otros pueblos europeos de que pueden avanzar a su manera al fin común [de todo el género humano]"162. Pero como tal garantía, si atendemos a la doctrina del equilibrio de potencias, ha de ser mutua, Fichte destaca igualmente que "la nación se mantendrá dispuesta para la guerra [...], cada ciudadano alemán será soldado y agricultor": existirá, pues, un ejército de ciudadanossoldados que, mediante ejercicios periódicos, estará siempre preparado para una veloz guerra ofensiva si fuera el caso 163 .

¿Podría una potencia alemana de estas características asegurar el equilibrio europeo frente a Francia? En lo inmediato, Fichte es consciente del carácter utópico del proyecto, pues transformar la pluralidad de principados alemanes -tradicionalmente apenas confederados- en un único Estado republicano dotado de un sistema representativo común parece casi imposible ${ }^{164}$. Pero más allá de las dificultades por consolidar una entidad política alemana, basta una mirada a la historia moderna para que Fichte descarte de raíz la doctrina del equilibrio de potencias como instrumento de paz. Tal doctrina, en efecto, depende de un supuesto esencial nunca explicitado por sus defensores: que exista un "botín al que nadie tiene derecho pero que todos desean por igual y que los mueve activamente a una auténtica rapiña universal"165. Es decir, las grandes potencias mantienen su equilibrio sólo mientras encuentran pueblos que someter y repartirse. Téngase presente, si no, el caso paradigmático -especialmente relevante para Alemania- de la confrontación entre las dos grandes monarquías universales del siglo XVII, Francia y los Habsburgo:

toda guerra surgida por el motivo que fuera había de decidirse en suelo alemán y con sangre alemana; toda violación del equilibrio había de restablecerse en aquella nación por ajena que fuera al origen de la situación; y los estados alemanes, cuya existencia independiente ya luchaba con-

\footnotetext{
158 Ibid. (GA, II/10, 389).

159 Ibid. (GA, II/10, 380-382).

160 Ibid. (GA, II/10, 410).

161 Ibid. (GA, II/10, 397).

162 Ibid. (GA, II/10, 412).

163 Ibid. (GA, II/10, 382).

164 Diarium (GA, II/15, 215-216).

165 RDN (GA, I/10, 269).
} 
tra toda naturaleza y razón, para ser algo tuvieron que convertirse en apéndices de los pesos principales en la balanza del equilibrio europeo, cuyo curso seguían ciega e involuntariamente166.

En suma, el sistema del equilibrio de potencias armadas como instrumento de paz en Europa es "un edificio doctrinal desacreditado"167 que, de por si, sólo puede conducir a "un silencio de las armas por cansancio pero con la intención de proseguir la guerra"168. Y, como ya había advertido Kant, no hay que confundir un mero armisticio con una situación de jure que, estableciendo una legalidad internacional, pueda asegurar una paz duradera ${ }^{169}$. Pensar políticamente Europa en función del equilibrio armado de sus Estados no haría más que contribuir a la realización del nacionalismo conservador particularista que mencionábamos antes. De ahí que Fichte regrese en 1812 a la letra del proyecto kantiano que había reseñado en 1796: sólo si “progresivamente todos los Estados entran en una federación, surgirá una paz segura y perpetua [...]; tal es el derecho, que se expresa él mismo en una federación de pueblos"170. Y esta doctrina, la única sostenible a priori, viene a coincidir fácticamente con las líneas de fuerza determinantes de la misma historia europea: el legado romano de la idea de derecho, su universalización jurídico-moral en el ius gentium cristiano, la tendencia federalista de los pueblos germánicos y las diferencias entre nacionales interrelacionadas. Por tanto, frente a la tradicional Realpolitik del equilibrio del poder, Europa sólo podrá vertebrarse políticamente como una federación de las naciones y pueblos cuya reciprocidad cultural la constituye entitativamente.

Ahora bien, Fichte no desconoce tampoco las dificultades empíricas que se oponen a que tal idea racional llegue a regular efectivamente el acontecer histórico. Por un lado, como la federación, si ha de efectuar "realmente" el derecho, ha de tener capacidad coactiva (interna y externa) - es decir, ha de estar armada-, se deduce que fácilmente "las fuerzas de la federación en manos del miembro más poderoso pueden convertirse en el medio de someter a los más débiles, con lo cual [tendríamos] propiamente una institución armada para la injusticia"171. Por otro lado, si los Estados miembros de la federación no son plenamente de derecho, la injusticia de uno repercutirá necesariamente en sus relaciones con los otros, generándose entonces una situación internacional de reciprocidad, pero no en el derecho, sino en su conculcación mutua ${ }^{172}$.

Kant ya había señalado la vinculación entre la realización los principios del derecho en un estado y en el plano internacional: "el problema del establecimiento de una constitución civil perfecta depende del problema de una relación exterior legal entre estados y no puede resolverse sin este último"173. Interdependencia entre derecho político interno y derecho de gentes que Fr. Schlegel había expresado en fórmula concisa: "el pleno republicanismo universal y la paz perpetua son conceptos recíprocos inseparables"174. Pero si tanto el derecho

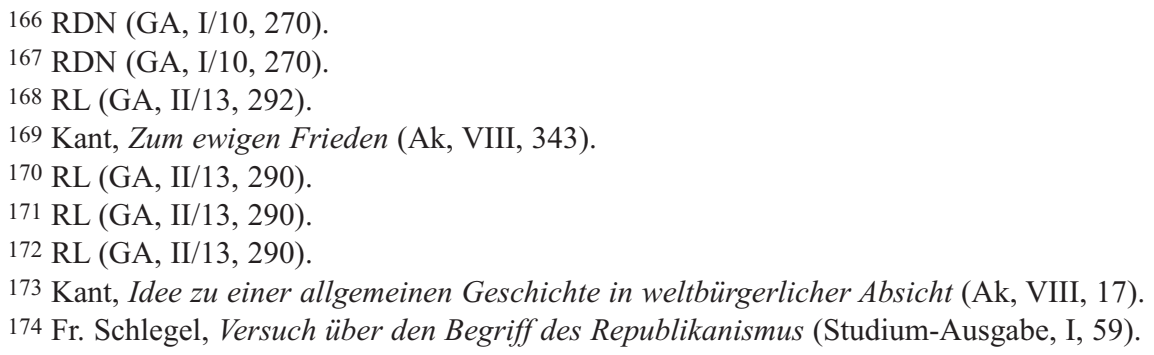


como la falta de derecho en la política interna y externa se condicionan mutuamente, ¿por dónde romper el círculo e iniciar la dinámica republicana y federalista? Fichte se pronuncia sobre la cuestión: "Yo digo: por [la injusticia] interna. De entrada [conseguir] el modelo de un Estado en sí mismo totalmente conforme a derecho. Tal Estado es, en parte, muy poderoso. Y por otra parte, la contemplación de su bienestar estimularía a los Estados vecinos para llegar a ser tan dichosos como él"'175. Es decir, la introducción de los principios republicanos en un Estado obraría a modo de polo de atracción para su extensión a otros Estados y provocaría progresivamente la instauración de organismos federativos entre ellos. Fichte ya había formulado en 1800 la misma idea en relación a la política económica: tan pronto como un Estado planifique racionalmente su economía, "este sistema se universalizará y se fundará la paz perpetua entre todos los pueblos"176.

Ahora bien, el último Fichte, al admitir, "después de maduras reflexiones”, la debilidad de su primera teoría del eforato como instrumento para impedir la extralimitación de los poderes en el Estado y su deriva despótica177, declara que "la tarea de instaurar el derecho [...] es una tarea del gobierno divino del mundo"178. Y con total coherencia, dada la reciprocidad entre el derecho interno y externo, lo mismo repite en relación al federalismo: "ciertamente puede afirmarse que no habría ninguna garantía [...] si no hay una federación de pueblos. Pero, ¿cómo alcanzarla? ¡Tarea irresoluble del gobierno divino del mundo!”179. ¿Significa esto que Fichte desvincula finalmente los ideales racional-jurídicos de nuestra esfera de acción, haciéndolos depender problemática y dogmáticamente de los designios de la providencia? En modo alguno. Si atendemos a las tesis del segundo período de la Doctrina de la Ciencia, lo absoluto-divino se manifiesta necesaria y eficazmente en la conciencia libre como constructora de la realidad. Por tanto, que el Estado de derecho o la federación internacional dependan del gobierno divino del mundo equivale a decir que dependen de la acción libre y racional. Ahora bien, ésta no queda reducida sólo a la esfera coactiva del derecho, sino que implica a la vez la dimensión educativa, cultural, religiosa y filosófica de la humanidad. Que los ideales jurídicos han de realizarse pero que, para ello, no basta sólo con el mecanismo legal-coactivo del derecho, significa a la postre que su efectuación depende de la concurrencia de aquellos otros elementos culturales esenciales para la formación humana, tanto en el plano individual como nacional.

En última instancia, pues, la "gran república europea de los pueblos" sólo podrá alcanzar sus fines racionales últimos si la dimensión jurídica, política y económica se vincula esencialmente a la cultural-educativa: "en la marcha hacia el reino [de la razón], la existencia de un estamento de profesores condiciona la existencia de una soberanía conforme a derecho"180. Y en la medida que las enseñanzas de tal cuerpo académico se basen en la "esquematización por la libertad" que (fácticamente) el mundo grecorromano, el cristianismo y los pueblos germánicos han anticipado y cuya verdad es demostrada (transcendentalmente) por la Doctrina de la Ciencia, será posible realizar la vertebración política de Europa

\footnotetext{
175 RL (GA, II/13, 290).

$176 \mathrm{gHS}(\mathrm{GA}, \mathrm{I} / 7,141)$.

177 RL (GA, II/13, 283-284).

178 RL (GA, II/13, 285).

179 RL (GA, II/13, 292).

$180 \mathrm{StaL}$ (GA, II/16, 77).
} 
según el principio del federalismo republicano: "engendrado a partir de las naciones germánicas y de las naciones que entren después con ellas en esa unión de pueblos"181.

Sin duda pueden resurgir aquí las ambigüedades de la dialéctica lingüístico-cultural entre "las dos partes de la nación común" y su superación en lo "alemán-universal". Como también se vislumbran los delicados problemas sobre cómo introducir en el Estado -mero "señor de la coacción" (Zwingherr) en sentido jurídico- un sistema racional de educación moral de los ciudadanos sin interferir en la intimidad de su conciencia, pues ello significaría una "coacción contraria al derecho, abominable y diabólica"182. Pero, en todo caso, queda claro que Fichte sólo concibe la vertebración política de Europa mediante una federación de sus naciones y pueblos que, privilegiando su dimensión filosófico-educativa universalista ${ }^{183}$, habrá de acabar con el mero equilibrio armado de potencias y extenderse a toda la humanidad hasta lograr la síntesis plena entre ius gentium y derecho cosmopolita. $\mathrm{Su}$ pronunciamiento póstumo al respecto, en la conclusión de su último curso académico en Berlín, es suficientemente explícito:

Así esto [implantación de un Estado cristiano-racional] incitará a los restantes pueblos cristianos a seguir su ejemplo y a apropiarse de las condiciones de su constitución y de su constitución misma que así se extenderá lentamente en todos los pueblos cristianos. Estos pueblos no se hacen la guerra y entre ellos existe una paz perpetua y una federación eterna. Con el resto de pueblos incivilizados no cristianos se encuentran en una guerra natural -0 , mejor, éstos con ellos. Indefectiblemente, la victoria no puede ser de éstos y esa victoria no puede tener más efecto que la incorporación de éstos al seno del cristianismo y, por imitación, a su constitución. Así, todo el género humano sobre la tierra será abarcado por un único Estado cristiano internamente confederado que, según un plan común, vencerá la naturaleza entrando en la esfera superior de otra vida 184 .

\section{Salvi Turró}

Universidad de Barcelona

salvi.turro@ub.edu

$181 \mathrm{StaL}(\mathrm{GA}, \mathrm{II} / 16,172)$.

$182 \mathrm{StaL}(\mathrm{GA}, \mathrm{II} / 16,67)$.

183 En este sentido, la tesis de F. Duque de que el futuro de la Unión Europa se juega en la función educativa que desempeñe su estamento profesoral universitario ("Política y moralidad en la Fenomenología hegeliana" en Hegel. La odisea del espíritu, UAM, 2010, pp. 223-224) sería, a mi parecer, más consistente de argumentar desde Fichte que desde Hegel. A menos que entendamos que el momento rememorativo-apropiativo (Erinnerung) -es decir, "formativo"- que permite el surgimiento del saber absoluto en la Fenomenología del Espiritu es más esencial al pensamiento hegeliano que el momento del espíritu objetivado en el derecho -derecho que, según Hegel, excluye cualquier forma de instrumento federativo internacional.

$184 \mathrm{StaL}$ (GA, II/16, 176-177). 